FINAL REPORT

PERFORMANCE PERIOD: August, 2007 - March, 2009

CONTRACT NUMBER: DE-FG36-05G085046

\title{
EVALUATION OF A LOW FRICTION - HIGH EFFICIENCY ROLLER BEARING ENGINE
}

\section{THE TIMKEN COMPANY}

Timken Technology Center

P.O. Box 6930

Canton, Ohio 44706-0930

Program Manager: Charles W. (Skip) Shattuck

Administrative Program Manager: Robert V. Kolarik II

Telephone: 330-471-2378

Mail Code: TEC-05

June 30, 2009

Prepared for

Golden Field Office

U.S. DEPARTMENT OF ENERGY

1617 Cole Boulevard

Golden, CO 80401-3305 


\section{DOCUMENT AVAILABILITY:}

"Reports are available free via the U.S. Department of Energy (DOE) Information Bridge:

Web Site http://www.osti.gov/bridge

Reports are available to DOE employees, DOE contractors, Energy Technology Data Exchange (ETDE) representatives, and Informational Nuclear Information System (INIS) representatives from the following source:

Office of Scientific and Technical Information

P.O. Box 62

Oak Ridge, TN 37831

Tel: (865) 576-8401

Fax: (865) 576-5728

E-mail: reports@osti.gov

Web Site: http://www.osti.gov/contact.html

Acknowledgment: "This report is based upon work supported by the U. S. Department of Energy under Award No. DE-FG36-05G085046“.

Disclaimer: "Any findings, opinions, and conclusions or recommendations expressed in this report are those of the author(s) and do not necessarily reflect the views of the Department of Energy" 


\section{EXECUTIVE SUMMARY}

This Low Friction (High Efficiency Roller Bearing) Engine (LFE) report presents the work done by The Timken Company to conduct a technology demonstration of the benefits of replacing hydrodynamic bearings with roller bearings in the crankshaft and camshaft assemblies of an internal combustion engine for the purpose of collecting data sufficient to prove merit. The engines in the present study have been more extensively converted to roller bearings than any previous studies (40 needle roller bearings per engine) to gain understanding of the full potential of application of bearing technology.

The project plan called for comparative testing of a production vehicle which was already respected for having demonstrated low engine friction levels with a rollerized version of that engine. Testing was to include industry standard tests for friction, emissions and fuel efficiency conducted on instrumented dynamometers. Additional tests for fuel efficiency, cold start resistance and other measures of performance were to be made in the actual vehicle. Comparative measurements of noise, vibration and harshness (NVH), were planned, although any work to mitigate the suspected higher NVH level in the rollerized engine was beyond the scope of this project.

Timken selected the Toyota Avalon with a 3.5L V-6 engine as the test vehicle. In an attempt to minimize cost and fabrication time, a 'made-from' approach was proposed in which as many parts as possible would be used or modified from production parts to create the rollerized engine. Timken commissioned its test partner, FEV Engine Technology, to do a feasibility study in which they confirmed that using such an approach was possible to meet the required dimensional restrictions and tolerances.

In designing the roller bearing systems for the crank and cam trains, Timken utilized as many production engine parts as possible. The crankshafts were produced from production line forgings, which use Timken steel, modified with special machining and heat treatment. Timken designed and manufactured all of the roller bearing related components such as the thrust bearing package. The production connecting rods and camshafts could not be used for the roller bearing engine, so new ones were produced according to the team's designs using Timken steel. The remaining miscellaneous components were designed and procured by FEV.

Timken prepared a display version of the crankshaft portion of the production engine without connecting rods which could be driven by a motor through a cogged-belt and electrically actuated clutch arrangement. A modified version was also made in which the engine was outfitted with roller bearings on the main bearing positions. Preliminary tests showed that the rollerized engine was running with $1 / 3$ less friction than the standard display engine. Additional friction testing and noise characterization was cut short because of shipping damage to the rollerized engine display and because of other project priorities.

The team did successfully demonstrate the ability to package roller bearings satisfactorily in numerous locations in a typical automotive engine. The scope of this project did not include durability demonstration and that subject would have to be addressed in any follow-on work. 
In the actual test phase, the rollerized engine did show significantly less friction in motored dynamometer tests compared to its production equivalent. The 5-10\% improvement measured in this study was about half that seen in other studies.

However, the fired test results did not show a reduction in friction which did not match prior experience or expectations. Subsequent teardown and inspection of the rollerized engine revealed potential sources of excessive friction in the experimental application. These features would be eliminated in a design not based on modification of production parts. The team is confident (based on experience) that friction reduction would be realized with proper modifications. 


\section{INTRODUCTION}

Bench mark studies quantifying the sources of energy losses in internal combustion engines have shown that friction in the cranktrain, which includes the crankshaft, bearings, pistons and connecting rods, accounts for as much as $50 \%$ of the energy losses at low engine speeds and up to $70 \%$ at higher speeds. Those studies, which indicate that half of those friction losses may be attributed to the connecting rod and main bearings, have shown the potential to improve vehicle fuel economy by as much as $5 \%$ through the application of roller bearing technology. While the potential has been demonstrated by several studies, the results have not been verified with sufficient rigor to convince conservative automobile engine designers to employ this bearing technology.

The proposed study was intended to apply roller bearings to the cam and cranktrains of a recognized well-performing production engine and to quantify the friction reduction and fuel economy in a series of industry standard tests. Due to time and resource constraints, attempts would be made to utilize standard components as much as possible with as few changes to the engine design as necessary. The intention was to develop a package of evidence that would convince the engine designers that additional performance testing of the bearing technology was warranted.

A well-recognized, experienced engine testing company, FEV Engine Technology, was selected to assist with the design effort and to conduct the majority of dynamometer and vehicle tests. The anticipated issues assuming the limited redesign approach were those of fit and interference. Extensive modeling was incorporated into the engineering plan to ensure that the best design was being taken into fabrication. Sufficient replication of tests was included in the test plan to provide statistical confidence. 


\section{FOREWORD}

The Technology Center of The Timken Company with its primary subcontracting partner, FEV Engine Technology (Auburn Hills, MI), conducted this program under partial funding from the U.S. Department of Energy (DoE) Award \#DE-FG3605G085046. This is the final technical report for the project entitled 'Evaluation of a Low Friction (High Efficiency Roller Bearing) Engine’ or LFE.

This report is structured to follow the work breakdown structure contained in the proposal for this project. In addition to commenting on the project management and technology background, it reports on the design and manufacture of parts need to modify a commercial internal combustion engine, the engine build, and the testing of the engine both on a dynamometer and in a vehicle. That testing was done to quantify the sources of engine friction and assess their impact on engine efficiency as measured by fuel economy in comparison to a stock engine.

The DoE project, which was administered by the Golden Field Office, with Dr. Dibyajyoti (Debo) Aichbhaumik serving as project manager. Ms. Pamela V. Brodie served as contract specialist, and Mr. Chad Sapp succeeded Mr. Brian Hunter as project monitor.

Timken's project team was led by Mr. Charles W. (Skip) Shattuck. Mr. Steven V. Boyd served as lead engineer and Mr. Dean E. Johnston, a retired Timken associate with considerable engine experience with rollerizing smaller engines, served as a consultant. Dr. Robert V. Kolarik and Mr. Michael R. Musacchia along with Mr. James L. Motylinski were the principals responsible for administering the project.

Significant contributions were made by Mr. Anthony P. Copper, Mr. Gary T. Schick and other members of the staff at Timken's Greenville (SC) facility. Engineering support was provided by Mr. Justin K. Brubaker and Mr. Cameron Gardella as well as members of the bearing design team located in Greenville including Mr. William A. Dammers, Mr. Christopher R. Abreu, Mr. Andrew J. Raycraft and Mr. Robert F. Lukasiewicz.

The FEV team was led by Mr. Floyd Allen with Mr. Brian Campbell under the direction of Mr. Joachim Wolschendorf and assisted by Mr. Pravin Sashidharan. Other members of the FEV engineering team included Mr. Nick Chomic, Mr. David Gian, Mr. Kiran Govindswamy, Mr. Yitzhak Henig, Mr. Henning Kleeberg, Mr. Michael McNally, and Mr. Joerg Ruwe with Mr. Jerry Graney and Mr. Stephen Kraemer supporting in procurement and contracting.

Other contributors to the project included Toyota Motor Corp. (Higashifuji, Japan and Ann Arbor, MI), InductoHeat (Madison Heights, MI) an InductoTherm Group Company, and ECM\&S (Torrington, CT). In addition, the following companies participated as suppliers to FEV: KP (Kellogg) Crankshafts (Jackson, MI), Schwartz Machine Co. (Warren, MI), Katech Inc. (Clinton Township, MI), Rody Machining (Plymouth, MI), and Hewitt Tool (Royal Oak, MI). 


\section{Table of Contents}

$\underline{\text { Item }}$

$\underline{\text { Title }}$

Page

A Project Management 1

B Background

B.1 Summary

B.2 Problem Description

B.3 Opportunity for Improvement

B.4 Proposed Solution

B.5 Potential Outcomes

C Proposed Objectives \& Deliverables

$\underline{\text { Task }}$

$\underline{\text { Title }}$

$\underline{\text { Page }}$

1 Timken Literature Study

2 Timken Display Engines

19

$3 \quad$ FEV

3.1 Feasibility Study

3.2 Detailed Design \& Part Procurement

$4 \quad$ Timken Bearing Analysis \& Selection

30

5 Timken/FEV Crankshaft Selection \& Manufacture

34

$6 \quad$ Timken Engine Testing

35

$7 \quad$ FEV Engine Testing

36

$\underline{\text { Item }}$

$\underline{\text { Title }}$

$\underline{\text { Page }}$

D Accomplishments

46

E Summary \& Conclusions

46

F Recommendations

46 


\section{List of Tables}

Number

7-1 Grid of BSFC Engine Mapping Points

7-2 Measurement Work Schedule
Title

Page

39 


\section{List of Figures}

Number

Caption

Page

B-1 Energy Utilization Cycle for the Internal Combustion Engine Vehicle

B-2 Energy Losses by Source in an ICE (courtesy FEV Engine Technology) 4

B-3 Normalized Energy Losses by Source in an ICE (courtesy FEV Engine Technology) 4

B-4 Hydrodynamic Wedge Formed in a Traditional ICE 5

B-5 Roller Bearing Operation in an Alternate Design for the ICE 5

B-6 Comparison of Friction in the Traditional and Roller Bearing ICE 6

B-7 Required Oil Flow in the Traditional ICE $\quad 7$

B-8 Required Oil Flow in the Roller Bearing ICE $\quad 7$

B-9 Application of Two-Cycle Engine Bearings $\quad 8$

B-10 Typical Engine Bearings (left), Engine Roller Bearings (right) 8

B-11 Photo of the VW 1.9 Liter TDI Diesel as Tested 9

B-12 Comparison of Torque Requirements. $\quad 9$

C-1 Proposed Project Plan 11

2-1 Plain and Roller Bearing Engine Displays. $\quad 19$

2-2 Main and Crank Pin Bearings on a Crankshaft. 20

3-1 Main and Connecting Rod Bearing Concepts. 22

3-2 Main Bearing Concept. $\quad 22$

3-3 Preliminary Thrust Bearing Concept. 23

3-4 Connecting Rod Bearing Concept. $\quad 24$

3-5 Cam Bearing Design Concept for \#2, 3, 4 Journals. 25

3-6 Production Oil Pump \& Intended Prototype Spacer. 26 


\section{List of Figures (cont.)}

Number

$\underline{\text { Caption }}$

Page

3-7 3-D Drawing of Outer Race and Rollers in Main Bearing Cap.

3-8 Seal Design Concept.

3-9 Toyota Avalon Test Vehicle.

4-1 Crankpin Bearing.

4-2 Main Bearing.

4-3 Crankshaft Thrust Bearing.

4-4 Camshaft Support Bearing.

5-1 Crankshaft Section Showing Hardened Zones

(a) Early Attempt (b) Refined Process).

7-1 2000 rpm with 2 Bar Load BSFC Data Point for baseline Engine

Compared to Database of Similar Engines.

7-2 Test Bench Schematic $\quad 40$

7-3 Baseline Engine Cranktrain Friction Comparison 41

Against Subcontractor Database of Similar Engines.

7-4 Motorized Friction Comparison of Production and

Rollerized Engines at Two Temperatures.

7-5 Customer Interface NVH Instrumentation 43

7-6 Powertrain NVH Instrumentation $\quad 43$

7-7 Full Load Speed Sweep - Driver's Ear Sound and Pressure and AI 44

7-8 Full Load Speed Sweep - Driver’s Ear Frequency Content $\quad 45$ 


\section{ITEM A}

\section{PROJECT MANAGEMENT}

Timken has more than a dozen years of experience performing R\&D contracts and working under government funding awards. Timken has developed and continues to use an internal accounting methodology with the rigor necessary to track costs on projects such as LFE. The cost tracking system has now incorporated the capabilities of the SAP accounting software recently implemented by the company.

Timken applied its project management rigor to the LFE project by incorporating a matrix management structure combining oversight by the Technology Center's Strategy \& Planning Group as well as technical oversight by the Bearings \& Power Transmission group. A formal project plan, timeline and budget were created by the project team and progress was monitored via monthly reviews during the course of the project.

A subcontracting agreement was reached in September 2007 with FEV Engine Technology, Inc. for engineering/design and testing services for the project. A feasibility study was conducted by FEV as a precursor to the main body of work for the LFE project.

The FEV organization is familiar with government funding and had several active DoE projects at the time of the LFE project. Weekly progress meetings were held with the FEV team during the course of the project to review the project schedule, discuss technical issues and decide direction.

Timken with input from FEV authored the quarterly technical reports and supplied them along with the required financial reports during the course of the LFE project. The FEV team also contributed to this final technical report. 


\section{ITEM B}

\section{BACKGROUND}

\section{B.1. Summary}

Internal combustion engines (ICEs) are the cornerstone of our modern industrial society. Unfortunately, the efficiency of these devices is relatively poor, the best of which are only capable of converting half of the fuel energy into useful work. More typically, the vehicles in common use waste four gallons out of every five in the form of heat and internal friction. In today's world where oil supplies are at the center stage of geopolitics, improving this situation is a critical step in achieving the country's energy independence.

The vast majority of internal combustion engines use fluid film bearings to support the inherent mechanical loads. These bearings are inexpensive and durable, but have two serious drawbacks. The first is that their operation depends on generating an oil wedge to support the loading. An inescapable part of this hydro-dynamic operation is that a large amount of energy is consumed in the shearing of this oil film and converting it to non-useful heat. In addition, oil film bearings require the uninterrupted supply of cooled, non-aerated oil under moderately high pressure.

Better technology exists in the form of low friction roller bearings. Because they generate their own oil wedge (elasto-hydrodynamic) with minimal fluid shear, these bearing have much lower friction characteristics. Roller and other types of anti-friction bearings are used in today's vehicles in every place where heavy loads and rotation are present (e.g., wheels, transmissions, differentials, accessories), except for those that carry the highest loads - the internal parts of the engine.

Working with the EPA, Timken has determined that internal engine friction can be reduced by $25 \%$ when the fluid film bearings on the crankshaft are replaced with roller bearings. In a vehicle, this friction reduction equates to a conservative fuel economy improvement of 5\%. Given the fact that this improvement can be applied to all vehicles and all internal combustion applications, this is a significant opportunity to save energy. Timken believes that even further improvements on oil independence can be made by utilizing other advantages of roller bearings that include major downsizing of the engine lubrication system to take advantage of the bearings' minimal requirements for oil supply and pressure.

Timken proposes a detailed, comparative study to convert an existing motor vehicle engine from fluid film to rolling element bearings and to document carefully the fuel economy and other benefits that result. In doing so, countermeasures will applied to address issues, such as noise, that traditionally have been given as reasons not to utilize the bearing technology. Timken plans to complete this study in a comprehensive manner that presents a solid business case for automotive and other manufacturers to adopt this fuel and lubricating oil saving technology. 


\section{B.2. Problem Description}

Internal combustion engines are very inefficient when it comes to converting fuel energy into useful work. The best of these (such as supertanker propulsion diesels) are only capable of converting half the fuel energy into work. As shown in Figure B-1 (courtesy of the DoE and University of Michigan) the ICE vehicles in use every day typically waste four gallons out of every five in the form of rejected heat and internal friction.

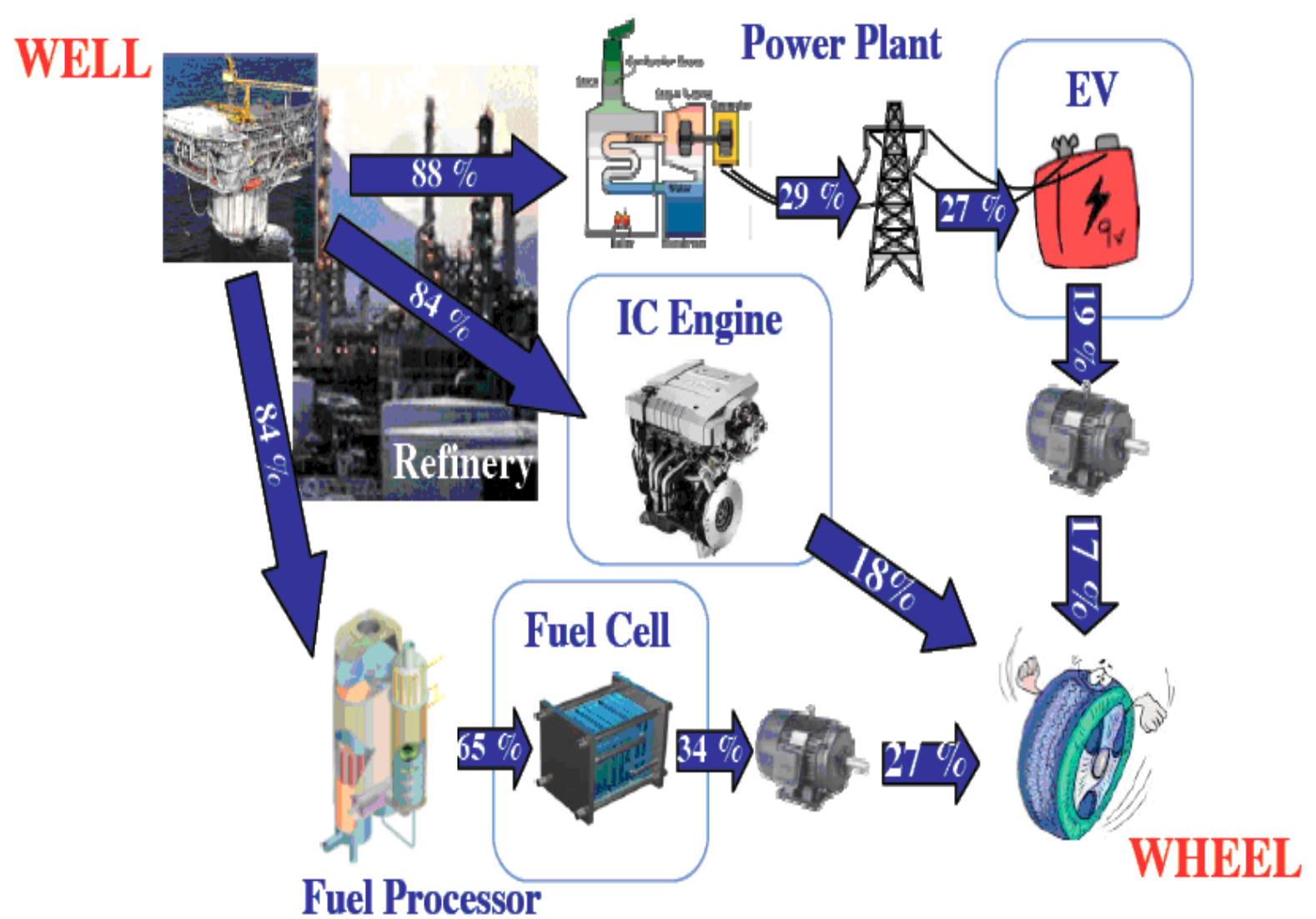

Source: Department of Energy

MichiganEngineering

Figure B-1. Energy Utilization Cycle for the Internal Combustion Engine Vehicle.

In recent years much work has been done on improving the ICE combustion process for better efficiency. Developments have included lean burn, variable valve timing, and direct fuel injection. These have had a very positive effect on fuel consumption. However, much of the gains have been offset by increases in vehicle power levels, weight and a larger global vehicle population. Surprisingly, little work has been done to reduce the internal friction in ICEs, despite the availability of technologies that offer significant improvements. 


\section{B.3. Opportunity for Improvement}

Examining sources of friction in a typical automotive engine, a large amount of friction is associated with the main and connecting rod bearings that support the crankshaft (Figure B-2).

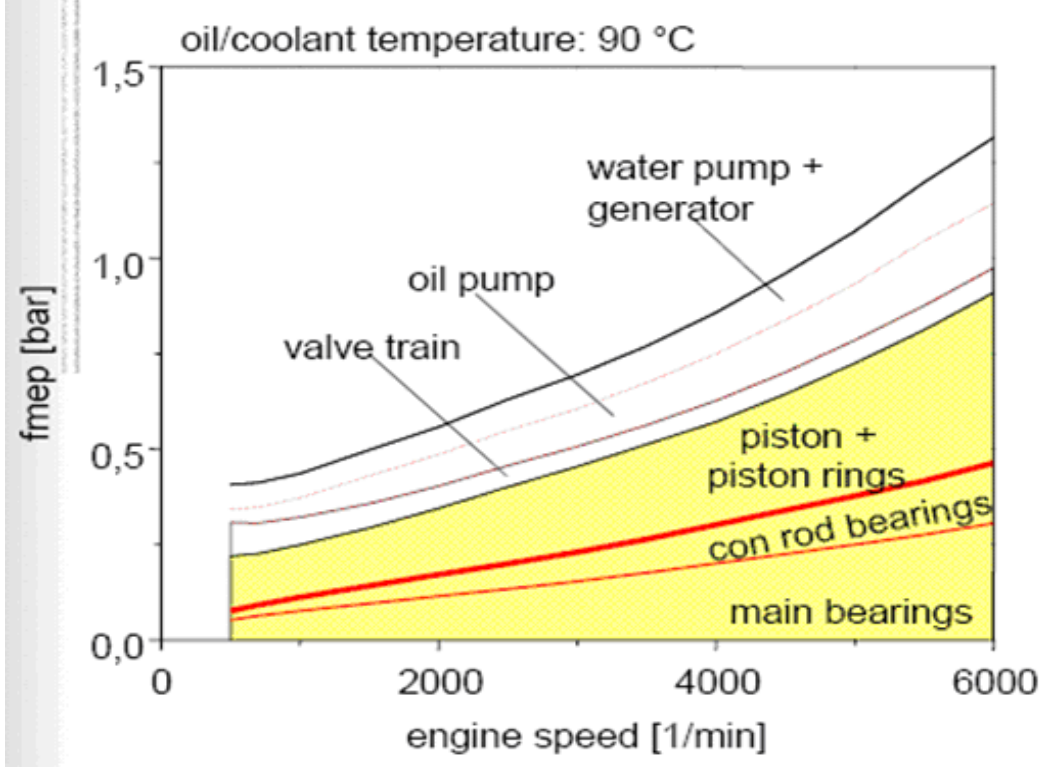

Figure B-2. Energy Losses by Source in an ICE (courtesy FEV Engine Technology).

The cranktrain is the part of the engine that is attached to the crankshaft and includes the crankshaft, bearings, pistons and connecting rods. Friction from these sources is shown in yellow, shaded area in Figure B-2. This accounts for about 50\% of the friction at low speeds and increases to about $70 \%$ at higher speeds. The portion of friction attributable to the crankshaft bearings is shown in the area below the red line. The same data are shown in Figure B-3, normalized as a percentage of total friction.

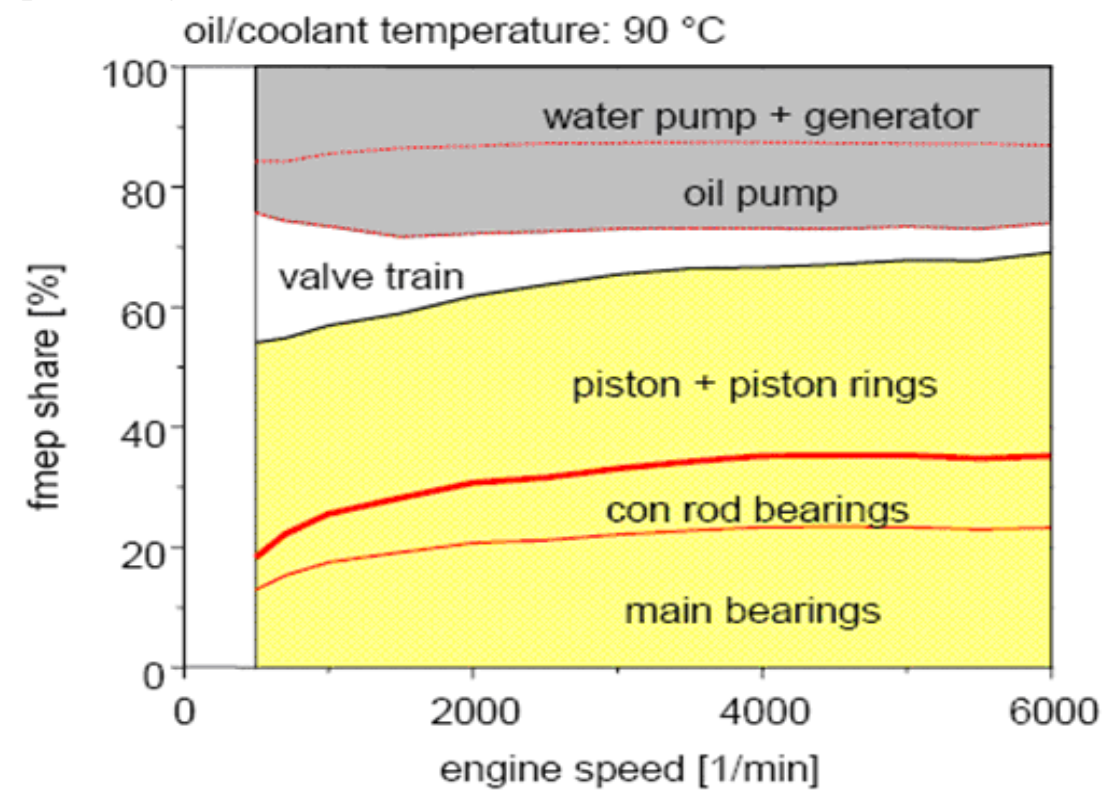

Figure B-3. Normalized Energy Losses by Source in an ICE (courtesy FEV Engine Technology). 
The major contributor to friction on the ICE crankshaft is the fluid film bearings that allow rotation of heavily loaded components (Figures B-4 and B-5). These bearings are durable and inexpensive, but have significant internal friction due to their method of operation:

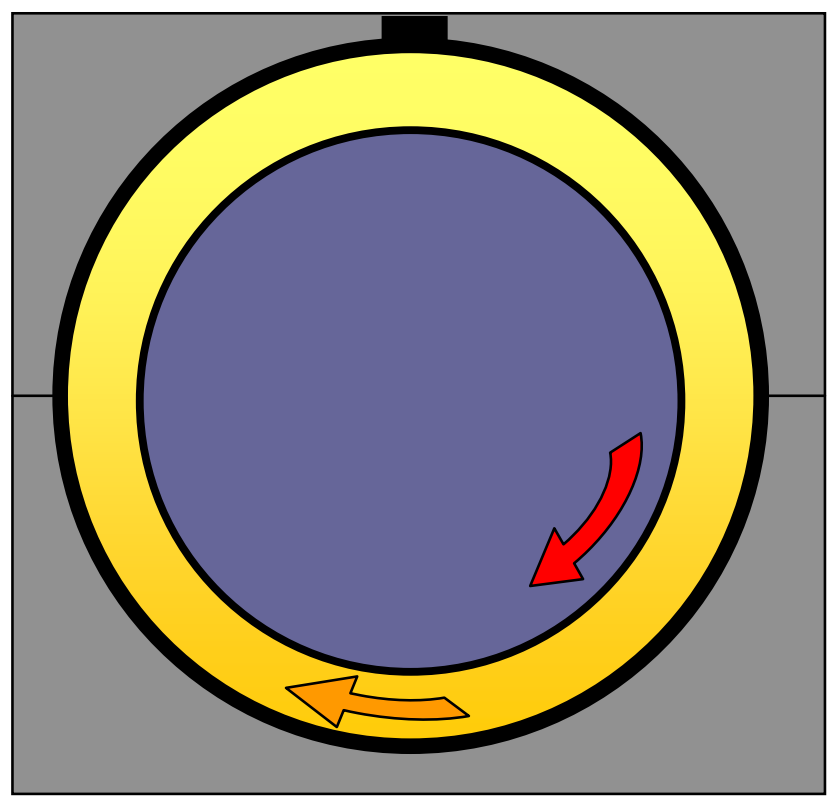

- Hydrodynamic oil film wedge supports shaft

- Oil film shear produces significant drag and heat

- Oil needs to be fed at high pressure to maintain film thickness and control temperature

Figure B-4. Hydrodynamic Wedge Formed in a Traditional ICE.

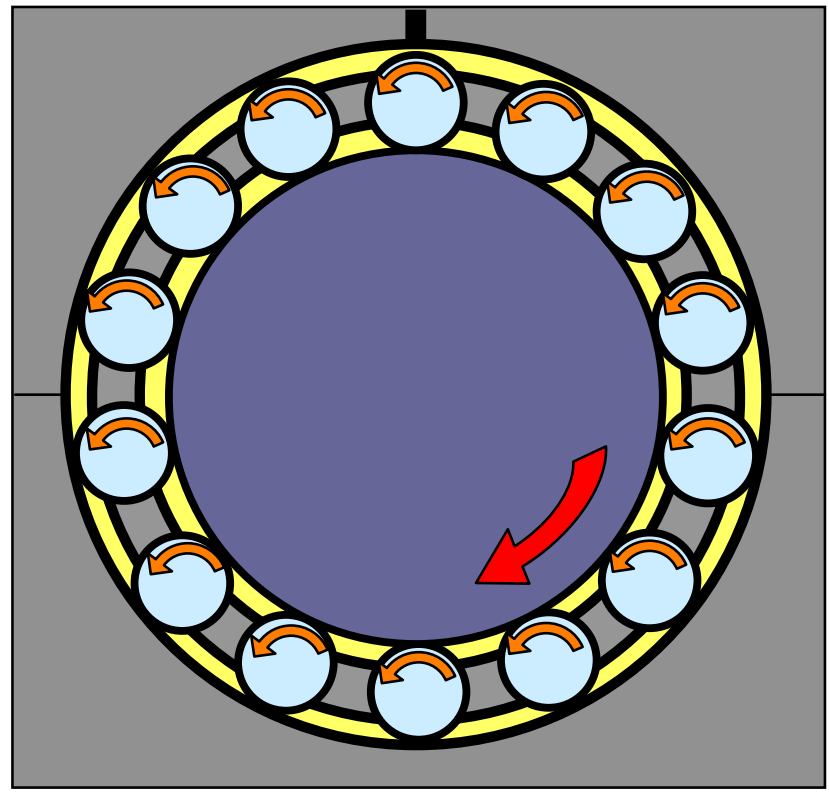

- Rollers support shaft

- Shaft rotation causes rollers to roll creating very little drag and heat

- Roller rotation creates hydrodynamic oil film between roller contact surfaces

- Requires very little lubrication to operate.

Figure B-5. Roller Bearing Operation in an Alternate Design for the ICE. 
The difference in bearing friction can be easily calculated and typical results are shown in Figure B-6:

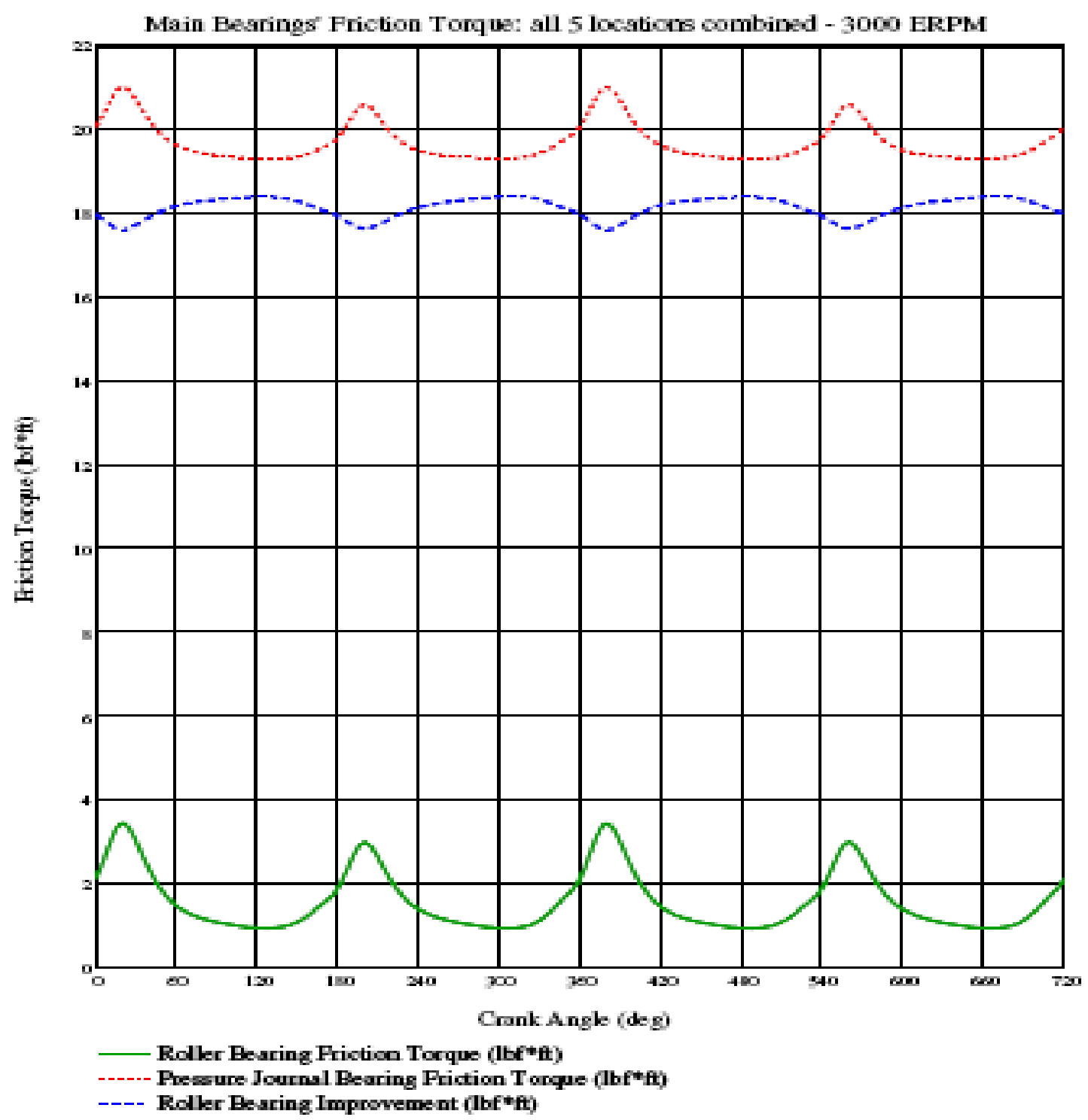

Figure B-6. Comparison of Friction in the Traditional and Roller Bearing ICE.

In this case, the lower, green line represents friction torque for the main bearings in a roller bearing equipped engine while the upper, red line shows the friction torque for the fluid film bearing version. The intermediate, blue line is the difference between the two.

Rolling element bearing technology is well developed and has been used in all heavily loaded vehicle applications (except engines!) for at least a hundred years. For example, the Timken Company invented the rolling element tapered wheel bearing in 1898. Today, this type of bearing or its lighter duty cousin, the ball bearing, is used in all vehicle wheel applications worldwide. 
An additional benefit of using rolling element bearings is that their requirements for oil quantity and pressure are minimal compared to fluid film bearings. Figure B-7 shows the oil pump output and distribution for a typical four-cylinder engine:

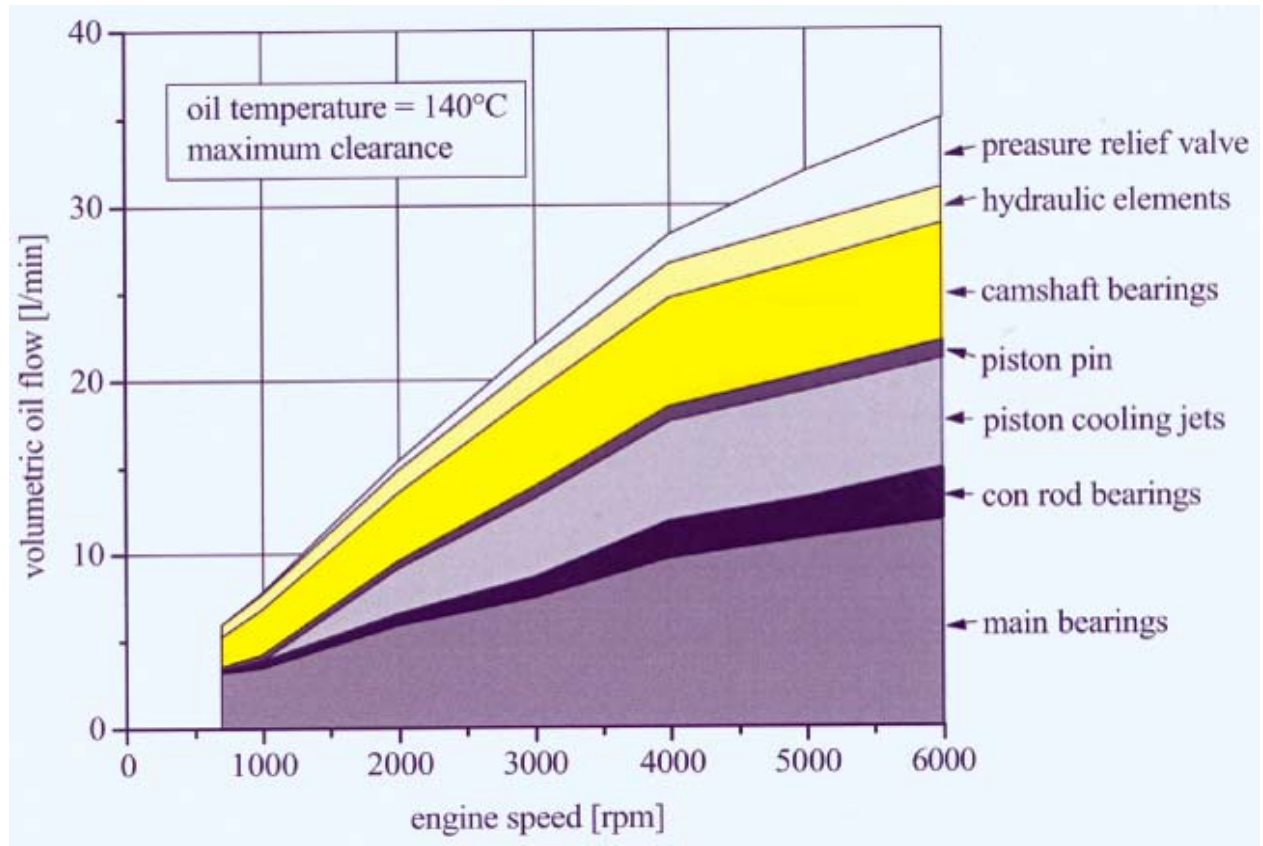

Figure B-7. Required Oil Flow in the Traditional ICE.

Figure B-8 shows the required flow for a rolling element bearing equipped engine:

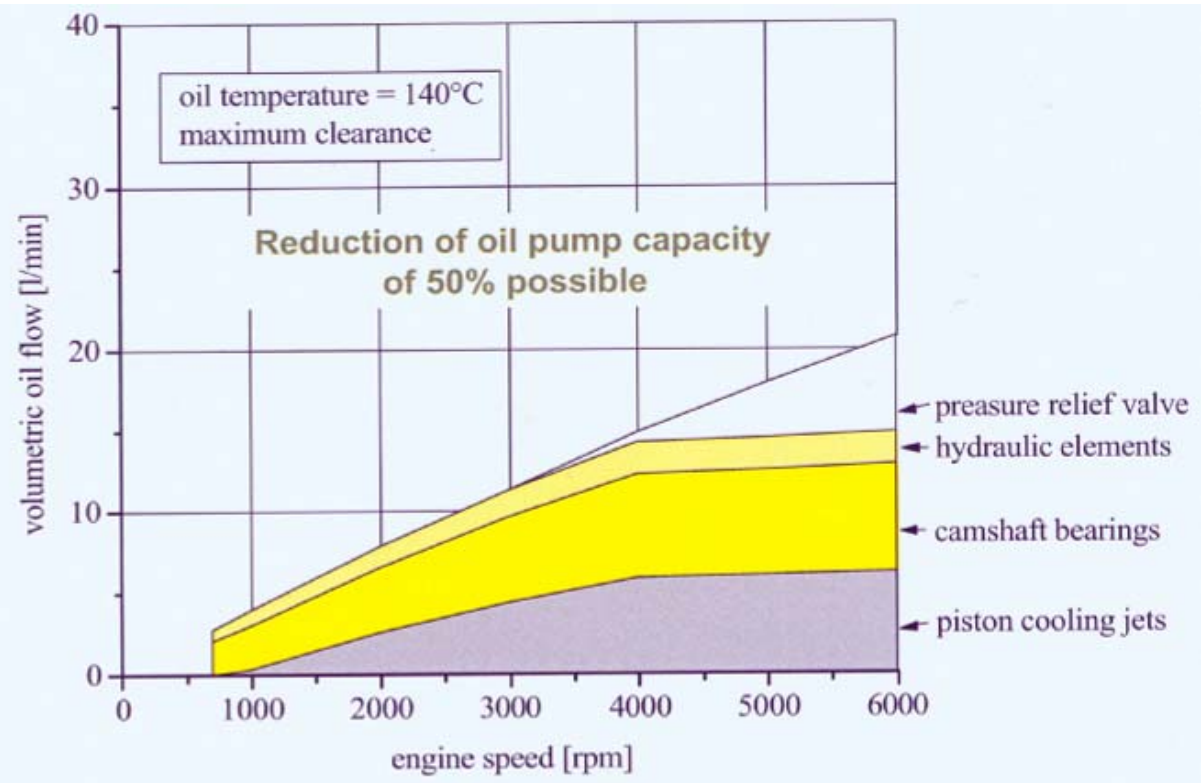

Figure B-8. Required Oil Flow in the Roller Bearing ICE.

This is a great secondary benefit since the friction lost to driving the oil pump is of the same order of magnitude as the fluid film bearings themselves. 


\section{B.4. Proposed Solution}

Timken has a long history of supplying roller bearings to the two-cycle marine engine business. These engines have grown to be in the same horsepower range as most of today's automotive engines. Timken proposes to use this technology to apply specialized versions of these bearings that would be suitable for high-volume, four-cycle automotive applications (Figure B-9).

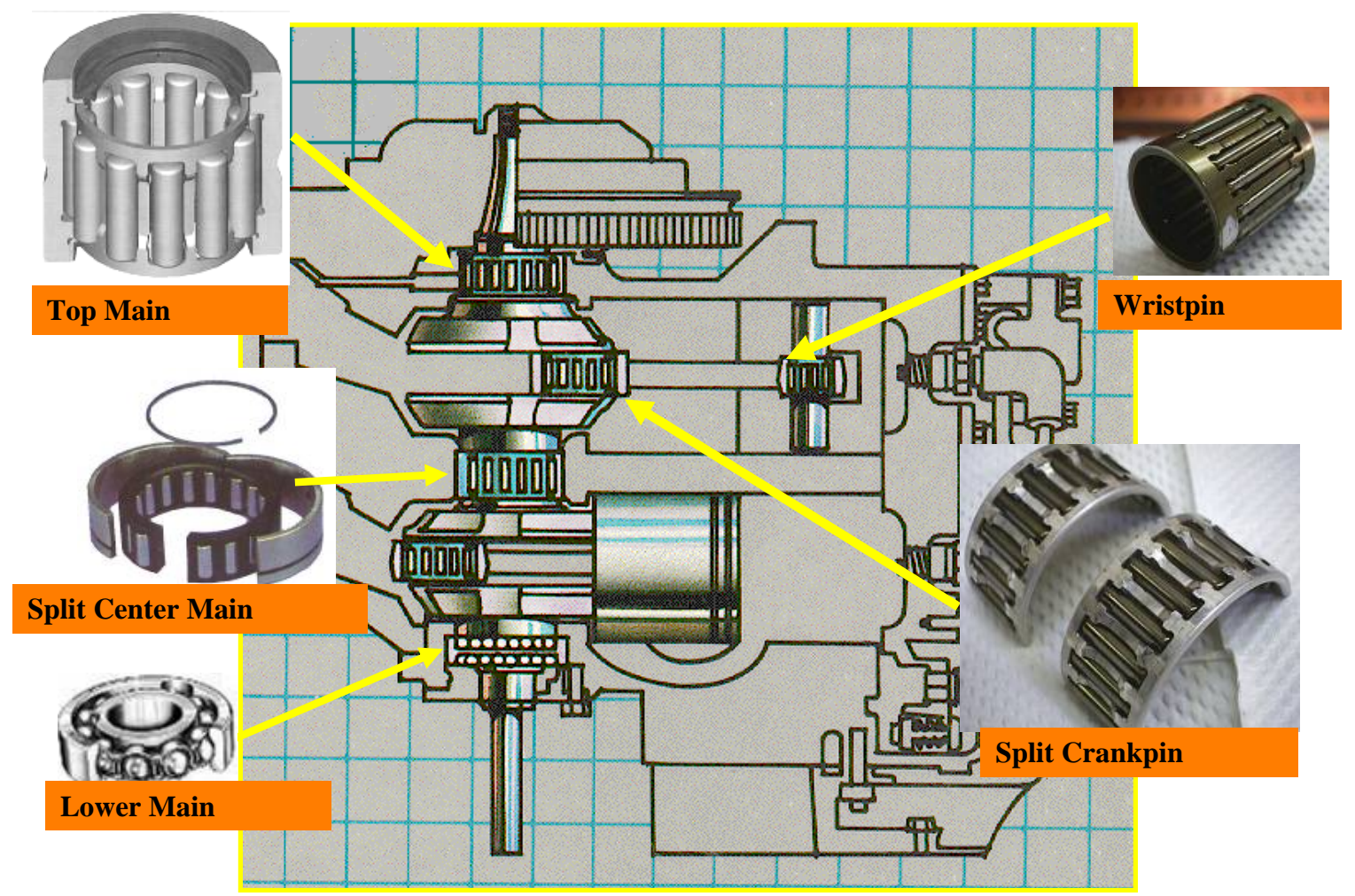

Figure B-9. Application of Two-Cycle Engine Bearings.

The concept is to replace the current fluid film bearing shells with specially designed two-piece split rolling element bearings which can be fitted around the hardened steel crankshaft and camshaft as shown in Figure B-10.

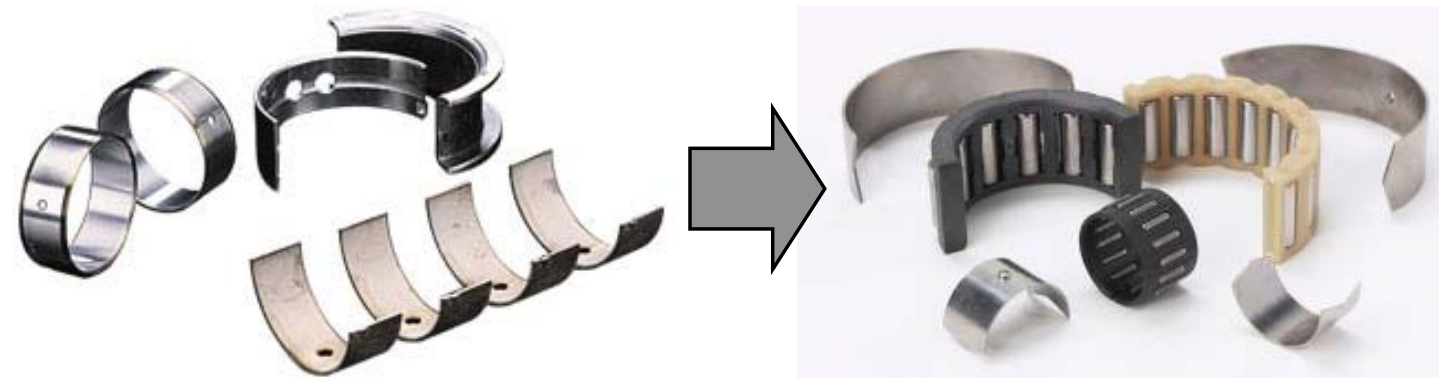

Figure B-10. Typical Engine Bearings (left), Engine Roller Bearings (right) 
Testing of a similar roller bearing arrangement (Figure B-11) in a joint program with the U.S. Environmental Protection Agency (EPA) showed a 25\% reduction in motored torque.

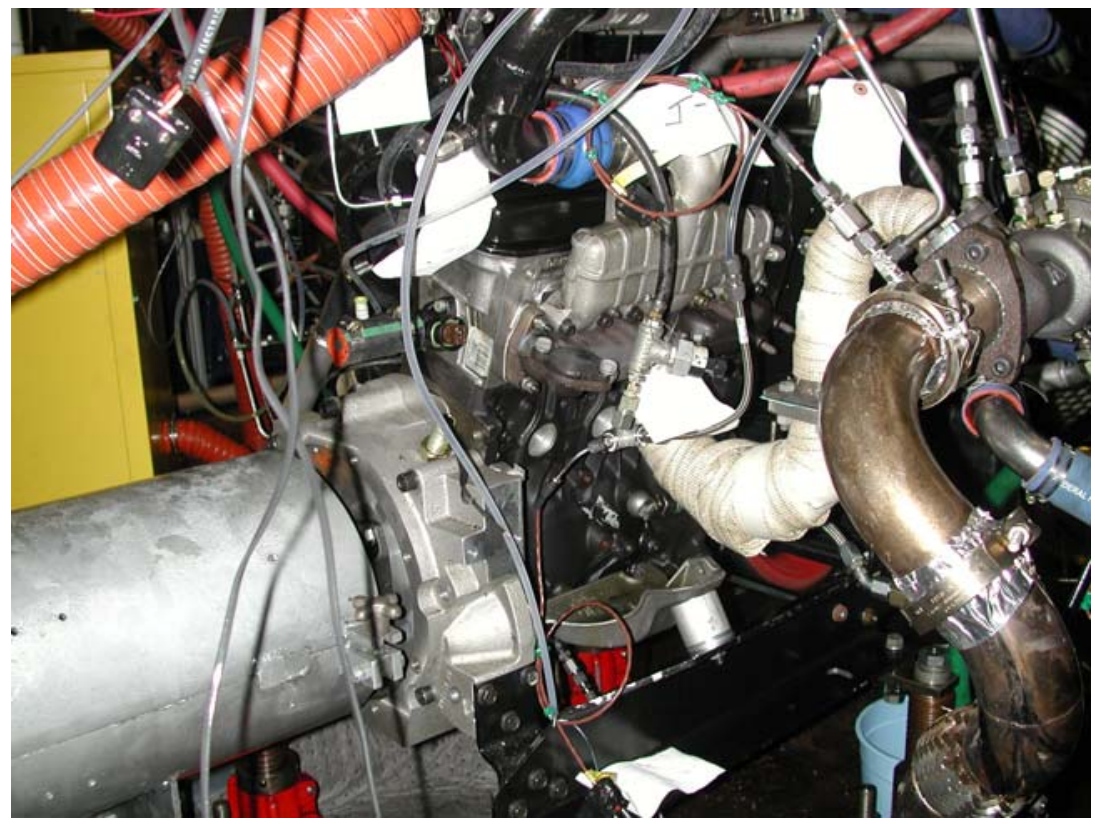

Figure B-11. Photo of the VW 1.9 Liter TDI Diesel as Tested.

Figure B-12 shows the motored torque curve for this engine with a $25 \%$ reduction in torque over the engine speed range. Included in this configuration is a $50 \%$ reduction in oil pump output volume accomplished by cutting the pump gears to half of their length.

Motoring Torque

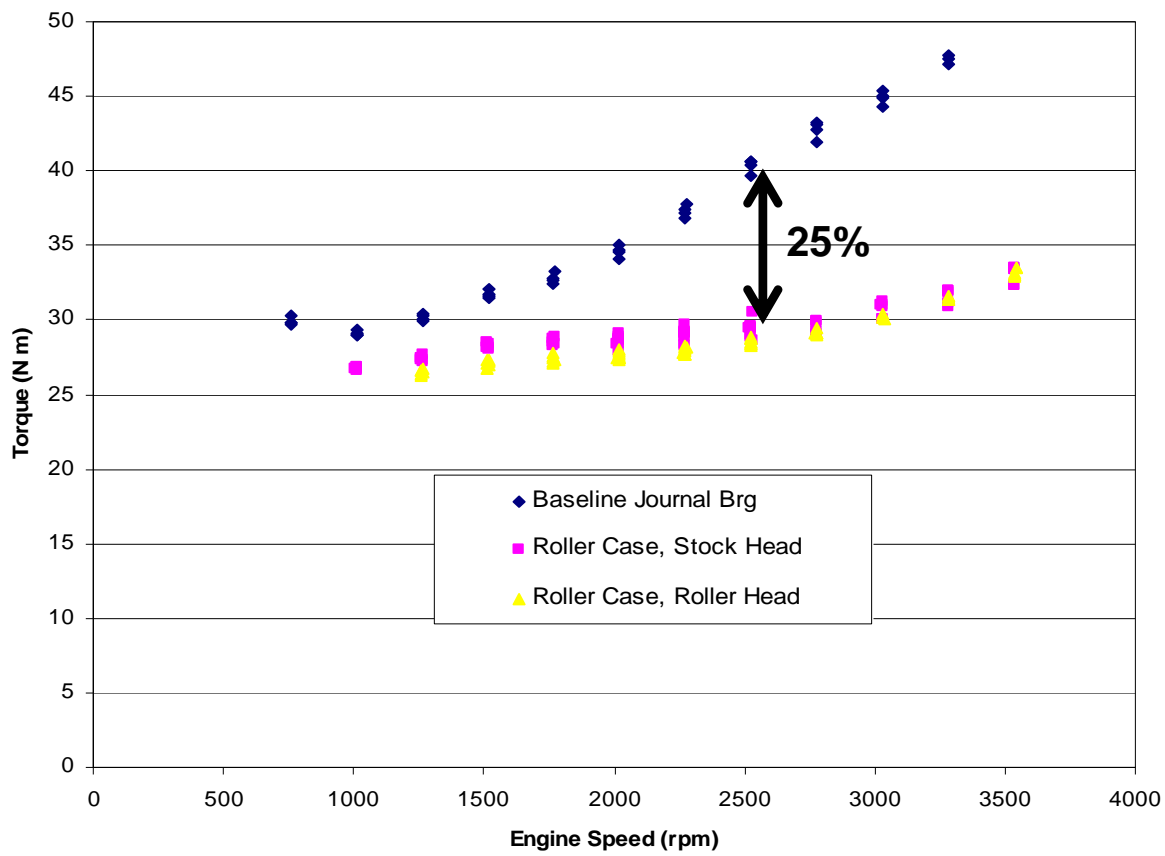

Figure B-12. Comparison of Torque Requirements. 


\section{B.5. Potential Outcomes}

\section{Upside}

There have been several studies that have explored the application of roller bearings approach to fuel economy improvement and each has come up with similar favorable results. The average improvement in engine friction is about $25 \%$ and vehicle fuel economy improves by about $5 \%$. This amounts to a saving of about 44 gallons of fuel a year for each average North American passenger car and 61 gallons for each light truck. Projected over the annual NA car production of 11 million units, this would amount to a 14 million barrel yearly savings of oil.

To put this into perspective, that savings equates to seven supertankers of oil that would not have to be imported. It gets better, since each year's production of more efficient vehicles would add to the savings. After 10 years of production the fuel efficient engines would be saving well over 100 million barrels, probably equal to approximately seventy supertankers of oil that would not need to be imported.

A study recently commissioned by Timken and conducted by FEV Engine Technology has concluded the roller bearing conversion of engines is a very cost effective way of improving fuel economy in comparison to other technologies that are being considered or have been implemented.

\section{Downside}

Biggest obstacle to conversion to roller bearing crankshafts is the paradigm that ICEs always use fluid film plain bearings. There is reluctance on the part of relatively conservative engine designers to stray too far outside the envelope on bearing system design. Although friction levels vary from engine to engine, as long as every OEM (original equipment manufacturer) uses fluid film bearings, everyone is pretty much in the same boat. Exacerbating this view is the lack of comprehensive data quantifying the advantages of rolling element crankshaft systems in statistically accurate terms that senior OEM engine executives can fully support.

\section{Timken Approach}

Working with the DoE and possibly an OEM, Timken proposed in this project to initiate a test program that would show conclusively whether the advantages of a low friction engine are sufficiently compelling to be considered for a production program. Timken believes that a well designed and administered program could quantify the improvements that have been shown previously on a limited scale. This program would also provide a chance to determine the viability of some other friction reduction opportunities that Timken feels would enhance the low friction engine performance characteristics. This test program would include the following professionally recognized test programs:

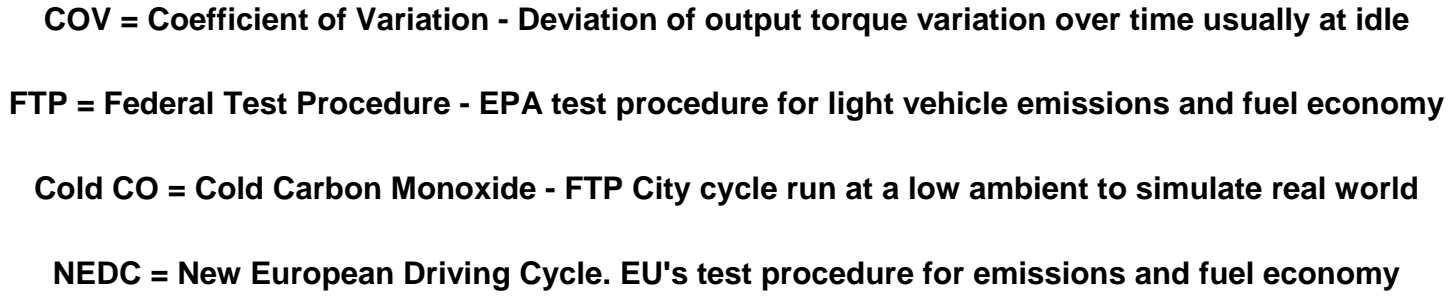




\section{ITEM C}

\section{Proposed Scope \& Deliverables}

In this project, Timken proposed to conduct a technology demonstration of the application of roller bearings to the cranktrain of an internal combustion engine for the purpose of collecting data sufficient to prove merit. The proposed objectives, project plan and deliverables are included below.

The primary objectives of the project will be as follows:

- to confirm the engine design by conducting durability tests of a modified selected commercial engine

- to quantify the friction reduction of the applied bearing technology

- to determine the impact of the technology on noise, vibration and harshness

- to determine the cold operation and fuel efficiency impact of the roller bearing engine

- to quantify the impact of potential reduction in lubrication volume

- to quantify the impact of potential benefits on a per vehicle and fleet basis

\section{Project Plan}

Timken will retain FEV Engine Technology to conduct the engine study. In the first phase, Timken, FEV with a crankshaft design specialist would select a candidate engine and specify the re-working of the engine. The program would procure multiple engines and Timken would supply the necessary bearing component sets. Durability and preliminary friction improvement and Noise, Vibration and Harshness $(\mathrm{NVH})$ studies would be conducted. The original project plan is shown below along with an outline of major tasks in each phase.

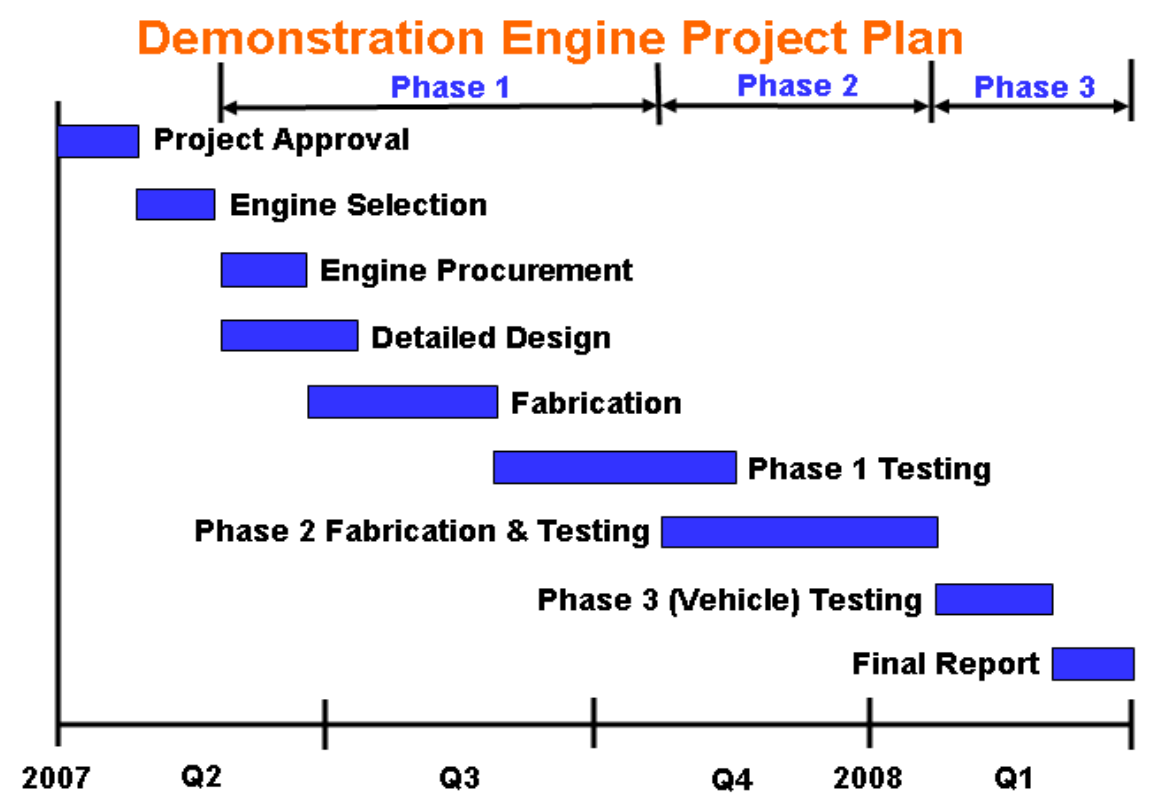

Figure C-1. Proposed Project Plan. 
Phase I Proof of Concept \& Preliminary Verification of Friction Reduction

- Feasibility of adapting rollers to selected engine

- Detail design of roller adaptation

- Procure production engines and adaptation parts ( 3 engines \& 5 sets of parts)

- Build prototype rollerized engines (3 engines)

- Proof of concept durability testing ( 2 engines $\mathrm{x} 50 \mathrm{hr}$ tests)

- Preliminary verification of friction improvement (motored \& world point bsfc measurement @ ambient (25C) \& normal operating (90C) temps) + check of idle instability (COV) (compare to existing data or run production engine)

- Preliminary engine NVH assessment (select critical points)

In the second phase, additional engines would be acquired; some engines would be used to conduct baseline testing and some modified with roller bearings based on lessons learned in the earlier phase. Friction and noise would be among the assessments made.

Phase II Detail Confirmation of Engine Level Friction, Fuel \& NVH Effects

- Procure 2 additional production engines

- Build 2 additional rollerized engines incorporating any Phase I learnings

- Map rollerized engines (bsfc \& output @ ambient (25C) \& normal (90C) operating temps + idle instability COV) - 2 engines

- Similarly map production engine to get baseline comparative data

- Use model to predict roller vehicle cycle FE benefit (FTP C/H, Cold CO, NEDC)

- Strip rollerized engine to quantify friction contribution of pertinent subsystems

- Similarly strip production engine to get baseline comparative data

- NVH fingerprint (idle + no load, part load and full load rpm sweeps) of rollerized engines -2 engines

- Similarly NVH fingerprint production engine to get baseline comparative data

- Develop NVH countermeasures if required for credible roller demonstration

In the final phase, extended testing, including fuel economy studies would be done aimed at providing evidence to convince the OEMs of the advantages of the roller bearing engine technology. 
Phase III Quantification of Vehicle Level Fuel, cold operation \& NVH Effects

- Run-in and baseline production vehicle cycle fuel economy \& cold operation (FTP C/H, Cold CO, NEDC, low ambient start characteristics) - 3 tests each

- Baseline fingerprint production vehicle level engine-related NVH

- Install rollerized engine in above vehicle

- Recalibrate as required to best demonstrate roller benefit

- Similarly run-in and vehicle test rollerized vehicle as above

- Similarly fingerprint rollerized vehicle engine related NVH

- Develop NVH countermeasures if required for credible roller demonstration

- Final report and assistance in OEM presentation material

The project deliverables would be in the form of reports documenting the results in comparison to engineering and baseline studies, as described below:

The deliverables of the project will be the following:

- Proof of Concept \& Preliminary Verification of Friction Reduction

- Detail Confirmation of Engine Level Friction, Fuel \& NVH Effects

- Quantification of Vehicle Level Fuel, cold operation \& NVH Effects

- Final report detailing the results obtained through development and testing in conjunction with all raw data collected during testing in csv format 


\title{
TASK 1
}

\section{Timken Literature Study}

A literature study was completed in 4Q2007, searching both Timken internal documents and any external publications on the use of anti-friction bearings in engine applications. Various publications were found and reviewed. Pertinent information on surface finishes, bearing clearance, lubrication, and $\mathrm{NVH}$ was gathered. A paper was found that showed significant efficiency benefits to using anti-friction bearings in a crankshaft application.

Below is a summary of highlighted references from the literature search showing the title, author and abstract along with some brief comments about the article, and how it may pertain to the LFE project.

\section{Search Criteria:}

"roller, ball or needle roller bearings in internal combustion engines supporting camshaft, crankshaft, and balance shaft"

\section{INVESTIGATION INTO THE USE OF ROLLER BEARINGS IN AN INTERNAL COMBUSTION ENGINE.}

McKenzie, Myron (Torrington Co); Lugosi, Robert Source: SAE Technical Paper Series, 1987, 8p, Publisher: SAE

\begin{abstract}
:
The efficiency of an automotive internal combustion (I.C.) engine is dependant on many factors such as combustion efficiency, thermal transfer efficiency, and mechanical efficiency. In this paper, the mechanical efficiencies of a fluid film journal bearing (crankpin) and a roller bearing operating under identical conditions are calculated. Comparisons between the two bearing types for various load and speed conditions are presented. Plots of heat generation, coefficient of friction, and oil film thickness versus speed are used to compare the two bearing types. The analysis indicates that frictional losses and heat generation may be reduced significantly if roller bearings were used in place of journal bearings in I.C. engine crankshaft assemblies. (11 refs.)
\end{abstract}

S. Boyd Comments from Article:

- Analytical comparison between journal bearing torque and needle bearing torque over a wide range of loads and speeds

- Shows analytically that there is an advantage to roller bearings over journal bearings, for use in automotive engines.

- Improvement increases with speed. Torque linearly increases with speed for both roller bearings and journal bearings. 


\title{
2. DESIGN FEATURES OF MODERN CONNECTING ROD BEARINGS
}

Luebbersmeyer, K. Source: Institution of Mechanical Engineers, Conference Publications, 1978, p 183-192, Publisher: Mech Eng Publ Ltd for Inst of Mech Eng

\begin{abstract}
:
With the increase of specific output power, the use of needle roller bearings for the support of connecting rods has become popular. This applies to small internal combustion engines, for both work principles i. e. two stroke and four stroke. In order to accommodate the high acceleration, light-weight cage designs with high strength characteristics have been developed. Particular attention is given to the guidance of the cages for both the piston pin and crankshaft position. Functional conditions and design features for both bearing assemblies will be explained with particular emphasis on high performance executions.
\end{abstract}

\section{S. Boyd Comments from Article:}

- Author is from INA

- Mostly deals with history and current design practices of 2-stroke engines. However, many comparisons are made to 4-strokes.

- Author makes note of using needle rollers in pre-selected groups - 2um grades for connecting rod bearings.

- A table is shown suggesting parallelism and roundness for the crankpin and conrod, along with suggested RIC. For example, the suggested RIC for a 30-40mm crankpin bearing would be $24 \mathrm{um}$ for a 2 -stroke and $22 \mathrm{um}$ for a 4 -stroke. $40 \mathrm{~mm}$ is the maximum size in the table. The LFE crankpin bearing is $53 \mathrm{~mm}$.

- The article makes note that with roller group sorting and matching of pin and conrod diameters, a RIC range of $\sim 12$ um can be achieved.

- The article also makes note that both bearing performance and sound are improved as RIC is decreased.

- Lubrication of thrust surfaces of the rod big end are important, notes the use of lubrication pockets (at least 4 for larger rods), and rounded corners to keep lube from scraping off.

\section{THE ROLLER BEARING ENGINE - A COST EFFECTIVE CONTRIBUTION TO $\mathrm{CO}_{2}$ REDUCTION}

Tiemann, Christof (FEV Motorentechnik GmbH); Orlowsky, Kolja; Steffens, Christof; Bick, Werner; Kalenborn, Markus Source: Proceedings of the Spring Technical Conference of the ASME Internal Combustion Engine Division, Proceedings of the 2006 Spring Technical Conference of the ASME Internal Combustion Engine Division, 2006, p 749-759, Publisher: American Society of Mechanical Engineers 


\begin{abstract}
:
The investigations and developments described in this article substantiate the potential for reduction of fuel consumption and the general feasibility of a roller bearing crank train in an internal combustion engine. An improvement of fuel consumption of $5.4 \%$ (NEDC) resulting from reduced friction was proven on the basis of a given 1.6L 4cylinder plain bearing engine converted to roller bearings. By means of subsequent calculations and simulations, the parameters for optimisation of the engine acoustics and durability were identified. Based on these findings, an advanced test engine was set up. Measurements with this generation 2 roller bearing engine demonstrate the expected significant improvement of NVH behaviour.
\end{abstract}

In parallel to the investigations with the generation 2 prototype which had to be a compromise with regard to robustness due to the requirement for a quickly realisable and feasible application, a completely new roller bearing bottom-end concept (generation 3) was developed. This new design meets the main requirements of optimal roller bearings while also taking the boundary conditions for high-volume production into account. The essential attributes of this generation 3 roller bearing crank train concept are the singlepiece conrod and main-bearing pedestals which are threaded onto a crankshaft with detachable counterweights. The extra cost of EUR 50-70 for these roller bearing engine concepts is on a low level compared to the achieved reduction in fuel consumption. Copyright (c) 2006 by ASME.

\title{
S. Boyd Comments from Article:
}

- FEV Aachen report based on Audi 1.6L 4-cylinder gasoline engine

- Roller bearings applied to crankshaft mains and con-rods. No camshaft roller bearings

- Fuel consumption reduction $\sim 5.4 \%$ based on NEDC, when compared to journal bearings

- $1^{\text {st }}$ generation testing used thin walled outer rings at main position. They had issues with roundness, clearance, and movement of these small rings.

- In their $2^{\text {nd }}$ generation design, they went to thicker outer races at the main position, and claimed much better performance, and lower noise.

- It appeared that their $1^{\text {st }}$ generation design utilized a cast crankshaft, which may have led to some of their initial issues. $2^{\text {nd }}$ generation went to case a carburized crankshaft.

- They found, but did not quantify an "optimum” RIC with respect to sound. Reducing RIC beyond this "optimum” value had no benefit.

- A $3^{\text {rd }}$ generation concept was developed, but not made or tested. This utilized a large split housing/main bearing OD that was bolted to the block. This removed the need for a separate outer race. It also utilized removable crankshaft weights and "threadon” connecting rods. 


\title{
4. QUALITY FOCUS UPGRADES TWO-CYCLE MOWER ENGINE
}

Stefanides, E. J. (Design News, Newton, MA, USA) Source: Design News (Boston), v 41, n 18, Sep 23, 1985, p 80-82, 84

\begin{abstract}
:
A new two-cycle engine maximizes the advantages of two-cycle mower powering through an overall design that increases precision/durability and reduces complexity. The increased precision is highlighted by a new 'fully jeweled' crankshaft/connecting rod system having high load-capacity, and antifriction bearings at every rotating joint. It utilizes large-diameter ball bearings at the crankshaft's main bearing journals and needle-type bearings at the crankpin journal and wrist pin.

S. Boyd Comments from Article:

- Not highly applicable to our project.

\section{NOISE AND VIBRATION REFINEMENTS OF THE FORD 3.8 LITER POWERTRAIN}

Albright, Michael F. (Anatrol Corp); Staffeld, Douglas F. Source: SAE Preprints, n 244, 1991, p 291-305, Publisher: SAE

\begin{abstract}
:
Continuous improvement of the NVH performance of current production power-trains is a necessary goal of domestic auto makers. In order to maintain a competitive product, it is necessary to re-evaluate proven hardware against demanding $\mathrm{NVH}$ performance targets established by the competition. This paper describes an $\mathrm{NVH}$ investigation of component modifications to the Ford 3.8 liter powertrain. The hardware investigated includes: ribbed and isolated rocker covers, drop-in roller fulcrums, forged steel and cast iron crankshafts, crankshaft bending damper, full skirt girdle, one piece bearing cap (bearing beam), reduced weight pistons and rods, ribbed sump, and alternate crank pulleys and water pump. At the conclusion of these investigations, a complete powertrain was assembled based on the recommendations generated in this project. The NVH features included in this 'quiet' 3.8 liter engine and the rationale behind the decisions are described. NVH improvements include sound power reductions of $4.9 \mathrm{dBA}$ at $1000 \mathrm{RPM}$ in neutral, $3.8 \mathrm{dBA}$ at $3000 \mathrm{RPM}$ under a drive load, and significantly improved vibration characteristics. As a result, the $\mathrm{NVH}$ performance criteria established by this 'quiet' 3.8 liter engine can serve as realistically attainable targets for further production level design refinement.

$\underline{\text { S. Boyd Comments from Article: }}$

- Abstract explains paper quite well

- Paper goes through many specific design iterations and modifications all in an effort to lower noise. The effects of these changes are specific to this engine design, but could offer ideas on areas to study for lowering engine noise.

- Lower weight pistons and rods for better low frequency noise

- Tighter running clearance lead to lower noise
\end{abstract}

\section{DEVELOPMENT OF THE MINIMUM FRICTION ADIABATIC ENGINE}


Kubo, I. (Cummins Engine Co, Columbus, IN, USA); Frisch, S. R.; Bryzik, W. Source:

AIAA Paper, 1984, 9p, Publisher: AIAA

\begin{abstract}
:
The Minimum Friction Adiabatic Engine program was initiated by Cummins Engine Company and the U. S. Army Tank-Automotive Command (TACOM) in order to research the feasibility of a significant reduction in an engine's mechanical friction. There are basically three areas which are unique for the engine: gas-supported piston assembly; solid lubricated ceramic ball and roller bearings for the crankshaft, crankpin, wrist pin, and turbocharger; and solid lubricated timing gears, camshaft, valve and injector-train bearings. Oil lubrication and water cooling of the entire engine, including the turbocharger, are eliminated. Based on computer calculations, a reduction in the engine mechanical friction of approximately $75 \%$ is estimated. Rig tests of each component have been completed and a single cylinder engine has been successfully operated. (7 refs.)
\end{abstract}

S. Boyd Comments from Article:

- Adiabatic engine design that utilized solid lubricated ceramic ball and roller bearings for crankshaft main, crankpin, and wrist pin positions. This lubrication method is not applicable to our application, but interesting.

- Discusses issues with roller skidding, the crankpin as a relation of engine speed vs. crank throw, crankpin diameter and roller diameter. 


\section{TASK 2}

\section{Timken Display Engines}

It was decided that building display stands of a standard engine and one equipped with roller bearings would be advantageous to understanding the rollerized concept and for getting a 'feel' for the impact of the reduced friction. In addition, the intent was to make some basic friction and sound measurements for comparison using those display engines.

A production engine block was procured and a second was modified with a crankshaft supported by needle roller bearings. The display stands were constructed so that each of these engines could be driven by an electric motor through a cogged-belt and electrically-actuated clutch arrangement. Both display stands were outfitted with provisions to measure the power required to spin the crank over a speed range of 500 to $1200 \mathrm{rpm}$. Preliminary figures indicated that the rollerized engine was running at 1/3 less friction than the standard engine.

The display engines (Figure 2-1) were shown at the SAE World Congress 2008 in April and later at a technical exchange with Toyota. Unfortunately, the rollerized display was damaged in shipment and delays in getting the desired crankshaft have limited the use of the stands beyond the display function. The stands have been repaired and are available for measurements.

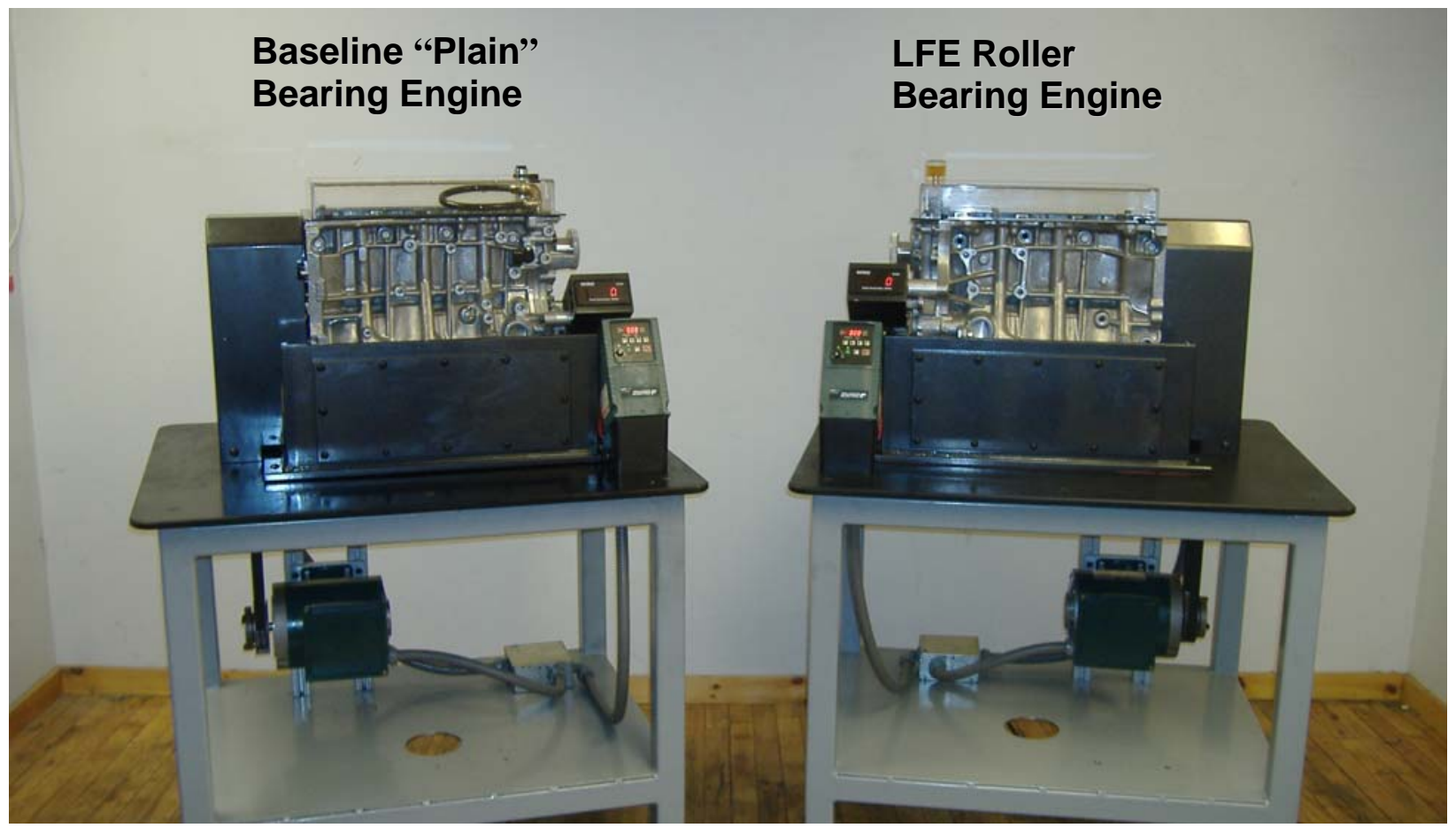

Figure 2-1: Plain and Roller Bearing Engine Displays.

To further illustrate the concept, a crankshaft was outfitted with prototype needle roller bearings. The resulting build-up is shown in Figure 2-2. 


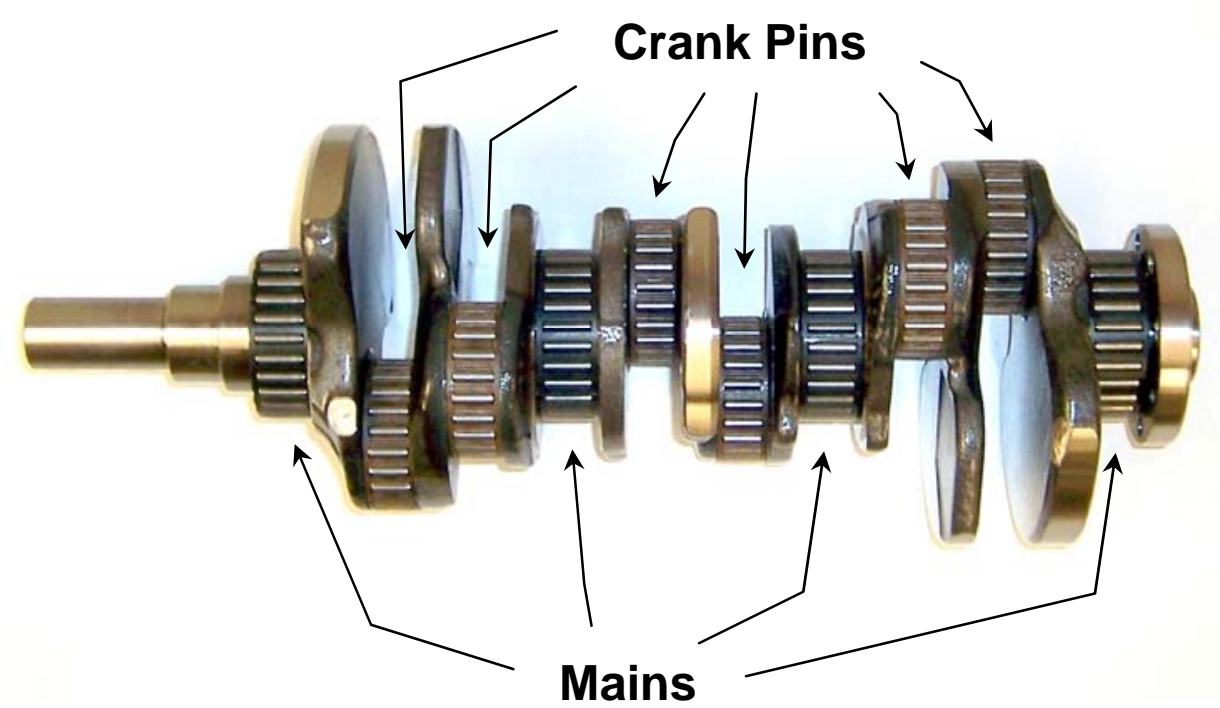

Figure 2-2: Main and Crank Pin Bearings on a Crankshaft. 


\section{TASK 3}

\section{FEV}

The project plan called for FEV to participate in the engineering/design phase of the project and to be the primary engine tester of the as-manufactured and modified engines. It was decided by Timken and FEV that it would be expeditious to conduct a Feasibility Study to investigate barriers to application of bearing technology, such as interferences, and to determine the best course to take to modify an engine for testing given the time and budget constraints. The results of the Feasibility Study conducted at FEV were reported to Timken and are summarized below.

\subsection{Feasibility Study}

In the early stages of the project when the decision was made to study the Toyota 3.5L V-6, it was unclear as to the level of support that would be provided by Toyota. Therefore, it was assumed that a demonstrator engine must be developed on a "make from" basis by making only machining modifications to production parts available commercially. In addition, the decision was made early on in the project schedule to focus the present study on characterizing the performance of the engine in terms of friction reduction and to defer long-term durability studies to a later time.

As a first step toward developing demonstrator engines, a Feasibility Study was conducted to assess the validity of the key assumptions related to fit and function. The Study was commissioned with FEV in September 2007 and completed in November 2007 with a summary report submitted to Timken. Among the components investigated were the main bearings, thrust bearing, crankshaft, connecting rod bearings, camshaft bearings and the oil pump.

Results of the Study indicated that main, connecting rod, and cam bearings could be implemented using a "make from" approach for the purpose of development of a limited service roller bearing demonstrator engine. Packaging studies indicated that sufficient space existed to accommodate bearings of the necessary size as determined from FEV and Timken experience and that sufficient lubrication could be delivered with only minor changes to the engine's lubrication system.

During the Study, the ability to procure or manufacture, as well as install the test components was addressed. Many of those considerations involved Timken's expertise in producing cracked races, split cages and properly sized needle bearing rollers. The sizes and tolerances necessary were defined in order to judge the ability to procure the necessary parts in a timely fashion. Preliminary specifications were generated and judgment was made that the necessary parts could be secured either from Timken or from engine component builders familiar to the project team. Figure 3-1 shows an example of the concept drawings developed for the main and connecting rod bearings. 

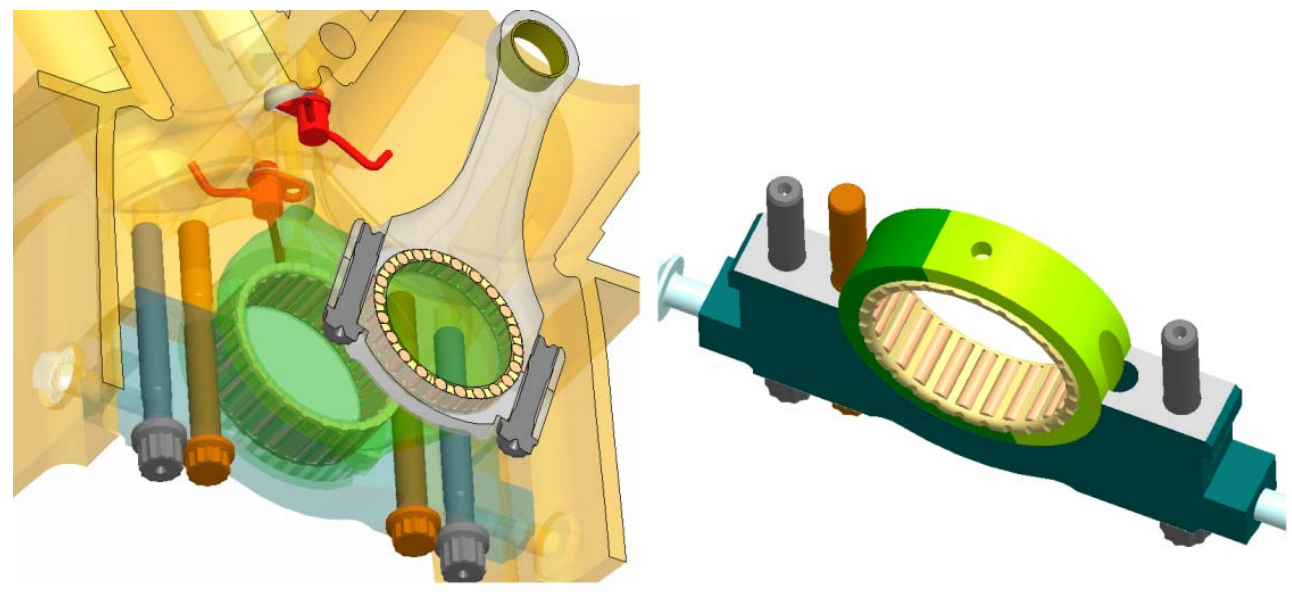

Figure 3-1: Main and Connecting Rod Bearing Concepts.

\section{Main Bearings:}

The concept explored for the main bearing outer races was to expand the housing bore to accommodate the bearing and to modify the attachment system to avoid interferences with the bolts in the cap. Initial Computer Automated Engineering (CAE) analyses of the main bearing/bulkhead/cap indicated that durability and contact pressure should be sufficient for a limited service demonstrator engine. The Study also attempted to predict the amount of distortion in the outer race of the main bearing and to guide the selection of a thin or thick-race design to minimize or control that effect. Additional CAE analyses and design studies were deferred to a subsequent phase of the project to address this and similar issues in detail. The original design for the main bearing assembly is shown in Figure 3-2.

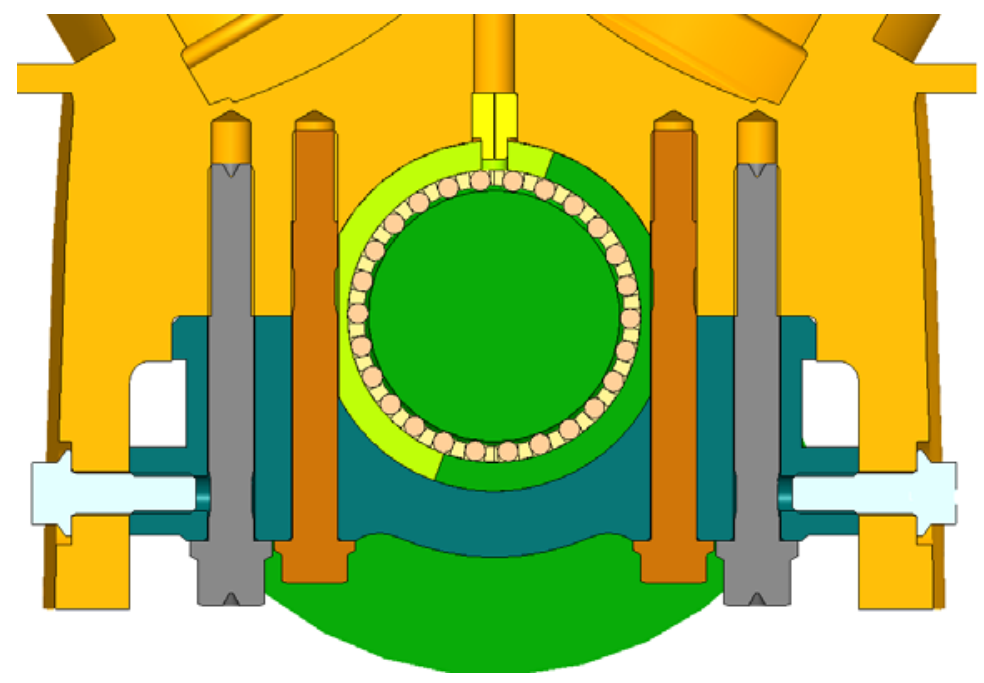

Figure 3-2: Main Bearing Concept. 


\section{Thrust Bearing:}

A preliminary design for the engine's thrust bearing was developed by Timken. The number one main bearing race would be a single continuous ring, and not a split design. The $3.5 \mathrm{~mm}$ thick washer labeled in Figure 3-3 transmits any forward or rearward thrust to the main race. For forward thrust, the crank face is the reacting member. For rearward thrust, the tone-wheel support collar is the reacting member.

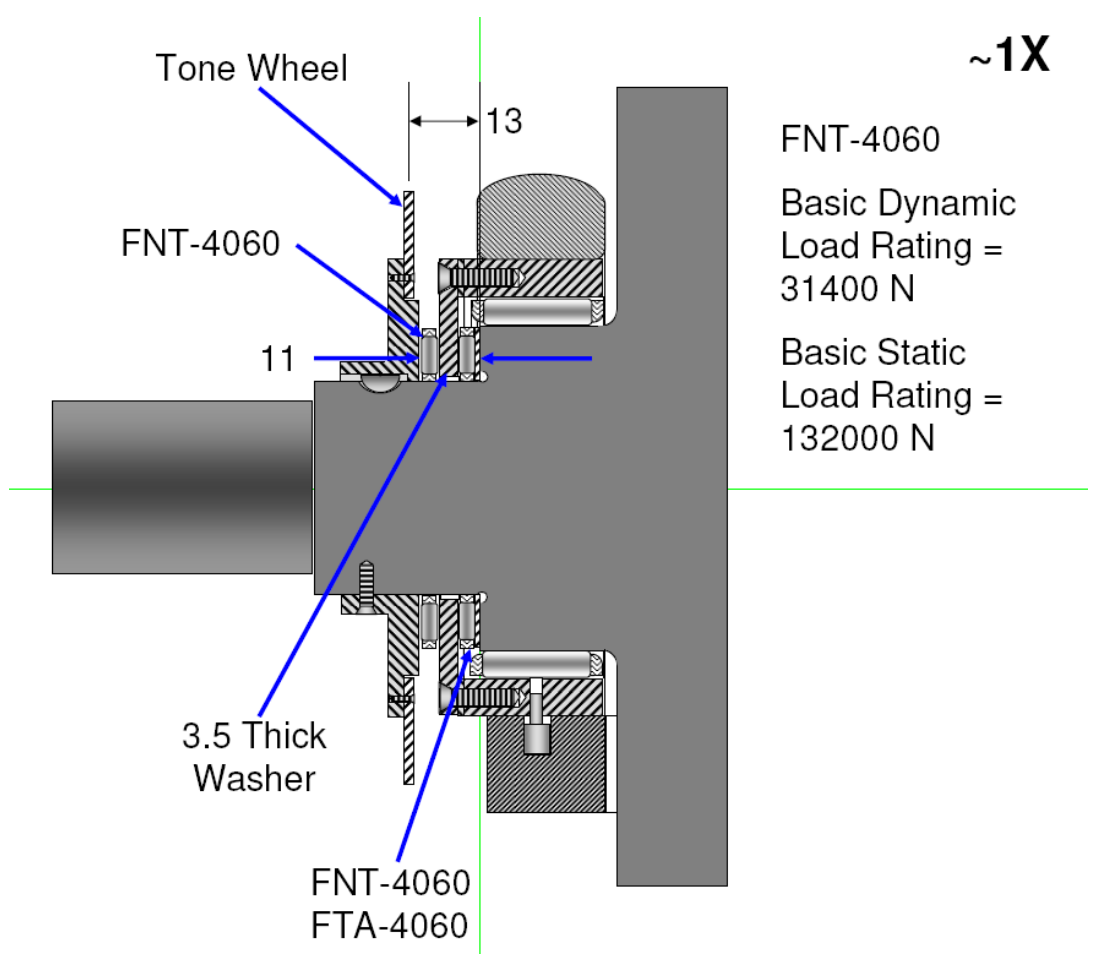

Figure 3-3: Preliminary Thrust Bearing Concept.

\section{Crankshaft:}

The following design assumptions for the crankshaft were made:

- The design should make use of the stock forging which would be provided to Timken by Toyota in a semi-finished state

- The nominal journal dimensions would be the same as the production shaft

- A minimum finished surface hardness of Rc 58 would be the target for all journals

The roller bearing engine would make use of the production crankshaft design with only minor modifications. The journals and pins would be induction hardened to provide appropriate running surfaces for the rollers. The nose of the crankshaft would be modified to suit a roller thrust bearing as discussed above. The nominal journal dimensions of the modified crankshaft would be the same as the production crankshaft. 


\section{Connecting Rod:}

The proposed connecting rod big-end bearing design concept is shown in Figure 3-4. The key challenge for the connecting rod would be getting sufficient oil to the rollers. Timken was confident that oil mist available in the crankcase would be sufficient to provide lubrication for the connecting rod bearing. Therefore, the connecting rod was designed to maximize oil mist entry to the bearing. It was agreed that modifications to the piston oil squirters to target oil at the connecting rod would not be made for initial engine testing. However, that issue remained an option should initial engine testing indicate insufficient lubrication.

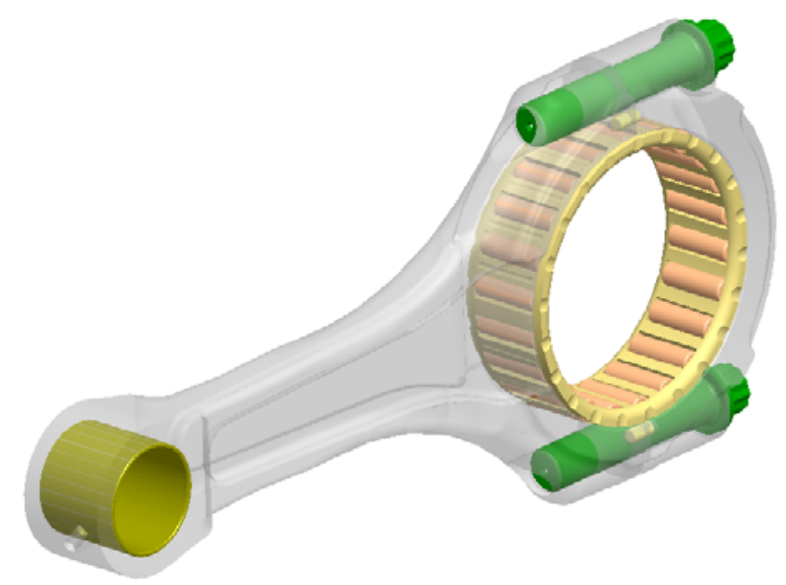

Figure 3-4: Connecting Rod Bearing Concept.

Assumptions

The following design assumptions for the connecting rod bearings were made:

- $5 \mathrm{~mm}$ rollers running directly on connecting rod and crankshaft surfaces

- A new design would be required to achieve adequate cap strength

- Retention of big-end guiding would be preferable

- Lubrication via crankcase mist would be sufficient

- No changes would be made to the production piston oil squirters

- Five roller size grades would be available with pin/rod/bearing matching to be done by Timken for tight control of radial clearance.

The new connecting rods would be machined from billet steel. The big end bore and big end geometry would grow to accommodate the $5 \mathrm{~mm}$ rollers. That expansion would leave about $1 \mathrm{~mm}$ per side of clearance for assembly through the cylinder bore. While this would not be ideal for production, it was judged quite sufficient for prototype purposes. The rod and cap halves would be aligned with dowels. 


\section{Camshaft Bearings:}

The following assumptions were made in the development of the cam bearing concept:

- Cam bearings \#2, 3, 4 can be a common design

- $1 \mathrm{~mm}$ thick race with $2 \mathrm{~mm}$ rollers

- Nodular iron cam shaft does not provide suitable running surface for rollers

- Cam bearing \#1 requires a unique design since it is an integral part of the VVT system (Timken will be responsible for this design)

The \#2, 3, \& 4 bearings would use Timken two-piece split bearing design. The production cam covers have spray bars, which spray oil on each cam lobe. There is one cam lobe adjacent to each journal. Therefore, adequate mist would be expected at each journal for lubrication of the needle roller bearing. The concept is shown in Figure 3-5.

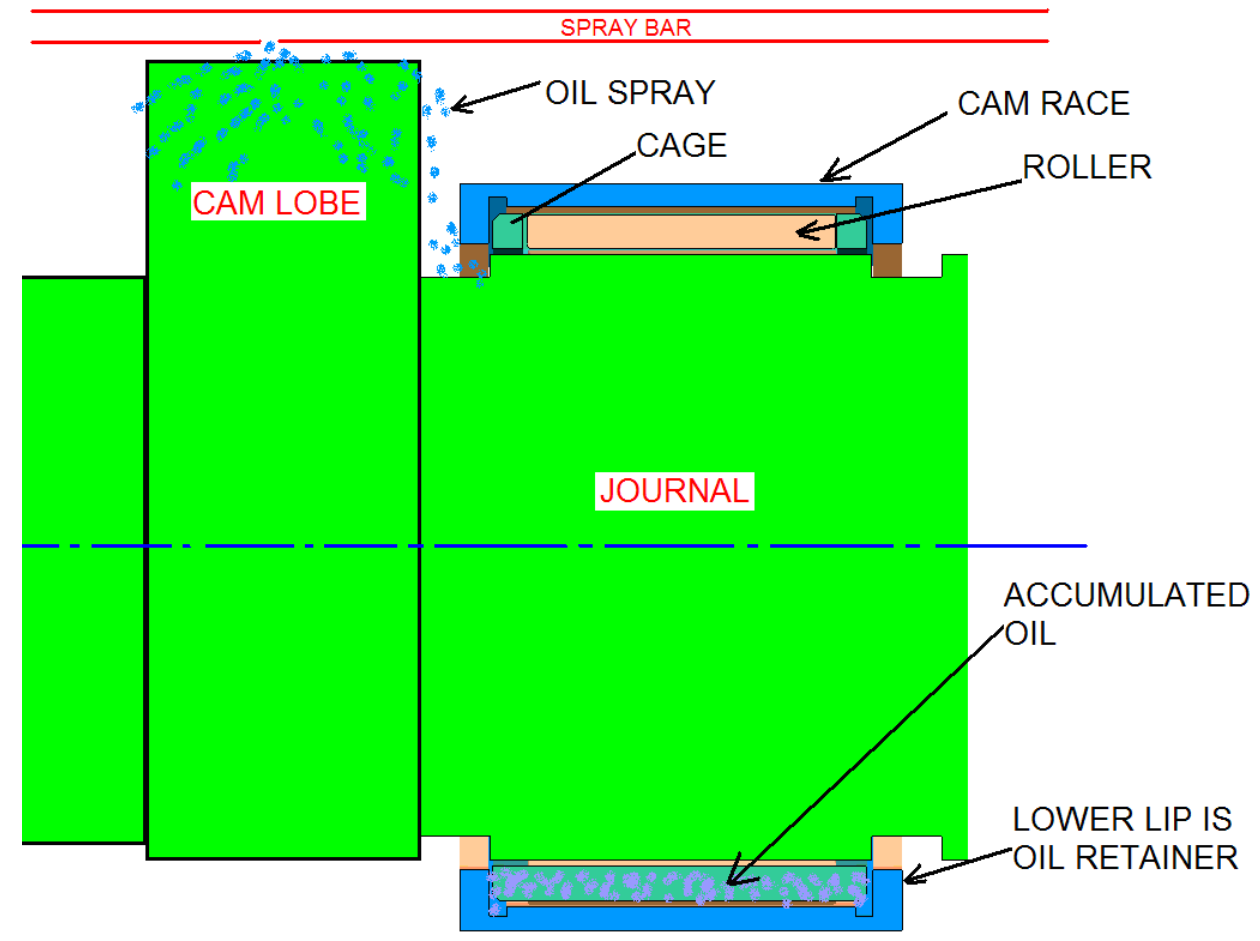

Figure 3-5: Cam Bearing Design Concept for \#2, 3, 4 Journals.

\section{Oil Pump:}

Based on FEV experience, a 40\% reduction in oil flow could be achieved while still providing enough flow for the remaining engine oil consumers. Therefore, the decision was made to reduce the rotor thickness by $40 \%$. The spacer shown in Figure 3-6 would be assembled between the rotors and housing. The large slots in the spacer ensure that the flow in and out of the rotor would not be restricted. The spacer was to be staked to the housing with blind-hole dowels. 

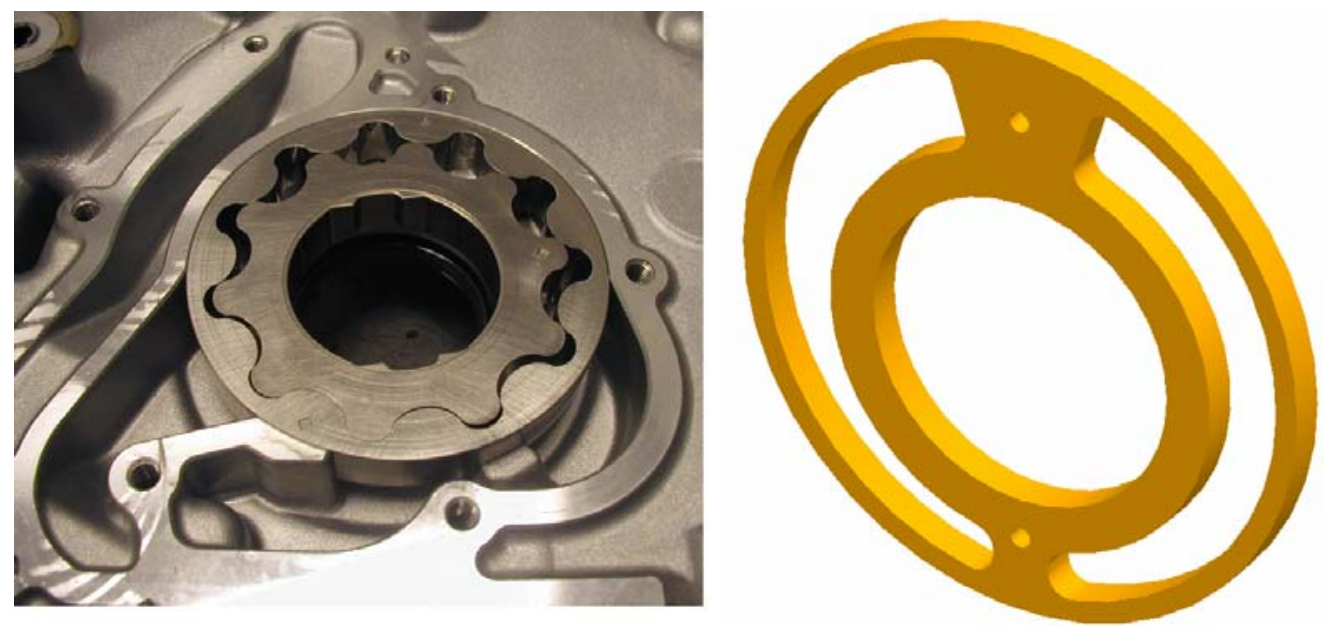

Figure 3-6: Production Oil Pump \& Intended Prototype Spacer.

With the favorable conclusion of the FEV Feasibility Study, Timken gave its approval to proceed to the next phase of detailed design and part procurement. In that phase, details were to be finalized around the concepts agreed upon in the Study including detailed bearing design using the concepts developed in the Feasibility Study as a starting point, assembly of demonstrator engines roller bearing for dynamometer testing of $\mathrm{NVH}$, performance, fuel economy, and durability. And finally, a vehicle would be outfitted with a roller bearing engine for NVH, fuel economy, emissions and performance testing to demonstrate fully the benefits of roller bearings in a V-6 engine.

\subsection{Detailed Design \& Part Procurement}

\section{Detailed Design}

The detailed design phase followed the original concept closely with two exceptions. The first involved the cross section of the main bearing outer races. The team was concerned about the out-of-roundness in the main bearing housing bores machined into the bulkheads in the engine block. While these would be very close to round at room temperature, thermal distortion at elevated temperatures could cause them to deviate from round. This condition would be exacerbated by the fact that the block is an aluminum alloy and the main bearing caps are steel. The difference in thermal expansion coefficients of the two materials is roughly two to one. In an effort to minimize the effects of this differential expansion, the thickness of the main bearing outer races had been designed unusually thick at $7 \mathrm{~mm}$.

However, extensive finite element analysis of the structure showed that beefing up the strength of the outer races had the detrimental effect of weakening the block bulkhead structure and causing additional out of roundness issues. After several iterations, it was concluded that a $3 \mathrm{~mm}$ outer race cross section was the optimum for bulkhead strength and outer race housing bore geometry. All subsequent components were fabricated to this standard. The revised design is shown in Figure 3-7. 


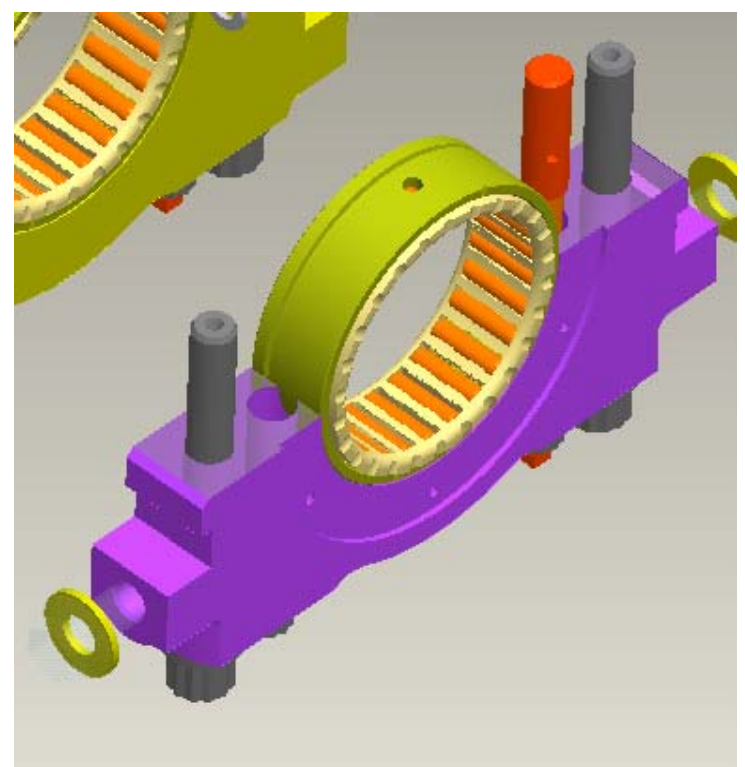

Figure 3-7: 3-D Drawing of Outer Race and Rollers in Main Bearing Cap.

The second major design change involved the front camshaft bearings. The overriding design principle had been to eliminate all of the hydrodynamic bearings in the engine and replace them with needle roller bearings. On the camshaft, the \#1 (forward) bearing carries the highest loads because it sees the timing chain tension as well as the loading from the adjacent valve springs. As such, it is a good candidate for roller bearing replacement to achieve friction reduction. However, this creates a problem with respect to the pressure oil feed to the hydraulic phasers used to control the valve timing in the engine.

The plain bearing in the production engine inherently seals the two fluid paths that control the phaser timing position. The roller bearing is much less restrictive in terms of oil flow and does not perform this function. Timken was able to develop a highly innovative design that incorporates three special seals to provide the required fluid paths along with the low friction roller bearing, all within the axial space available. This design is shown in Figure 3-8.

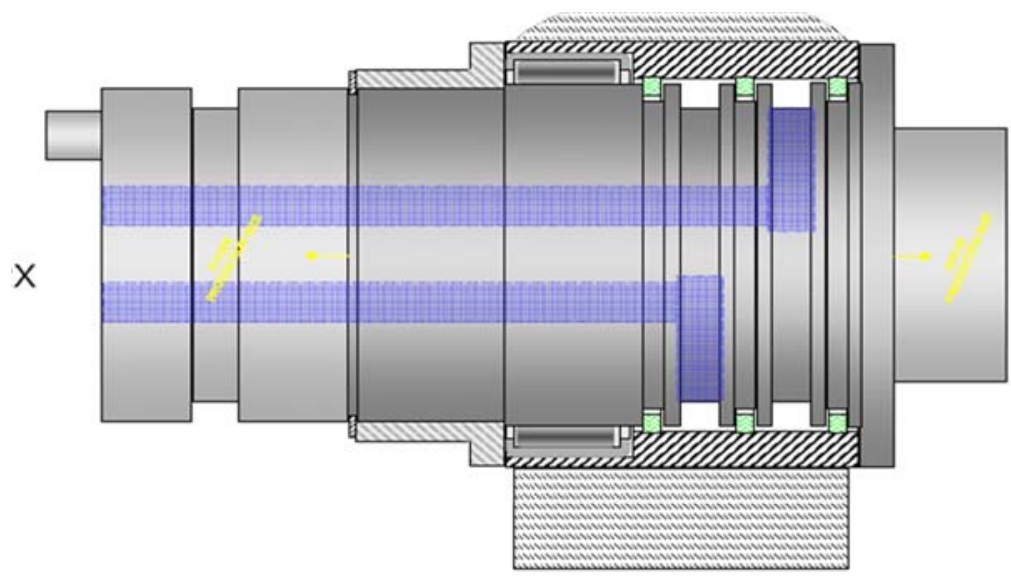

Figure 3-8: Seal Design Concept. 


\section{Part Procurement}

\section{Vehicles:}

The project plan called for testing standard and rollerized versions of the engine on a dynamometer and eventually in a vehicle. The Toyota 3.5L V-6 was the standard engine in the 2008 Highlander and Avalon models. As the Avalon version was produced domestically in Kentucky, it was decided to use it as the test vehicle in the event that local sourcing might be an advantage. Two vehicles were purchased, one for use as a test vehicle and one as a 'mule'. In the mule, the vehicle's wiring package was used to satisfy the safety interlocks and to control the engine as if it were running in the vehicle. The 2008 Avalon test vehicle is shown in Figure 3-9.

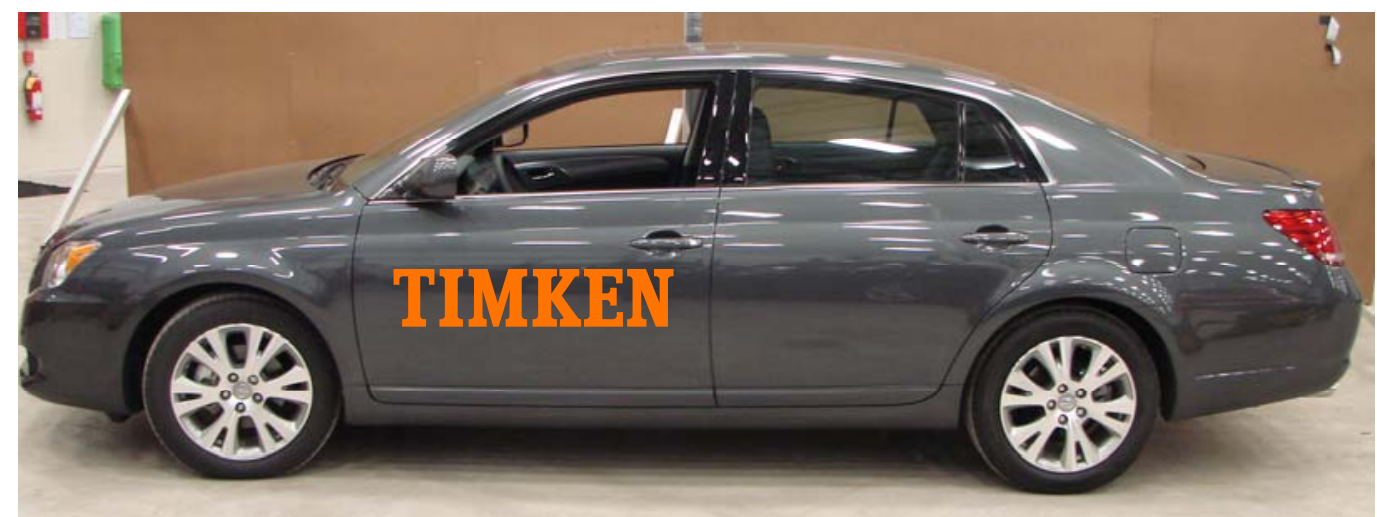

Figure 3-9: Toyota Avalon Test Vehicle.

\section{Engines:}

Because of the sequencing of tests and the scheduling of engine builds, additional long-blocks (engine without intake and accessories), short-block (block and rotating assembly), and bare blocks were purchased to make up the desired number of finished and test engines.

\section{Components:}

Where possible, modified production components were used. In the case where that was not possible, such as connecting rods and camshafts, new components were made to the team's design specifications by specialty vendors. The approach taken was to procure or manufacture parts in sufficient quantity to allow flexibility of processing or recombination in an engine modification.

\section{Crankshafts:}

Timken was confident that crankshaft material should provide adequate performance for a limited duration test as Timken was the supplier of the steel for the cranks. Partially finished crankshafts were procured from Toyota's production line. A further description of the processing is included in a later section. 


\section{Connecting Rods:}

Because detrimental inclusions were discovered in the steel procured for the rods, a billet of suitable Timken grade steel was substituted. The connecting rods were machined from the Timken bar stock, heat treated and finish ground.

Camshafts:

The camshafts, each of the four having a unique configuration, were also machined from Timken bar stock.

\section{Bearings:}

The components of the bearings were manufactured in various Timken plants in the U.S.A. and Europe. A further description is included in a later section. 


\section{TASK 4}

\section{Timken Bearing Analysis \& Selection}

During the analysis and anti-friction roller bearing selection phase of this project, Timken used the knowledge gained from many years of rollerizing various types of engines for marine, automotive and motor bike/cycle applications.

The Toyota 3.5L V-6 engine was analyzed for bearing loads approximating the peak power condition. The analysis begins by calculating crankpin bearing loads, incrementally through the $720^{\circ}$ combustion cycle based on the gas pressure loads of combustion, the inertia loads from the mass of reciprocating components and the inertia loads from the epicyclical motion of a portion of the mass of the connecting rod.

The crankpin bearing load, used to calculate bearing life, is computed using a conventional, weighted calculation to determine a single "equivalent load". This is done by summing the incremental loads (p1, p2, ... pN) at each angular increment (i1,i2, ... iN) through the $720^{\circ}$ combustion cycle, then calculating the weighted average load.

$$
\text { Equivalent Load } \left.(\mathrm{Pe})=\left\{\left[(\mathrm{p} 1 @ \mathrm{i} 1)^{10 / 3}+(\mathrm{p} 2 @ \mathrm{i} 2)^{10 / 3}+\ldots+(\mathrm{pN} @ \mathrm{iN})^{10 / 3}\right)\right] / \mathrm{N}\right\}^{3 / 10}
$$

The main bearing loads are based on the six sets of incremental crankpin bearing loads acting on adjacent main bearing journals in the sequence defined by the engine's firing order and at the relative angular position, or increment, of each crankpin during the $720^{\circ}$ combustion cycle. The portion of the crankpin bearing load applied to each main is proportional to the distance between each crankpin journal center of load and main bearing journal center of load. Like the crankpin bearing loads, a single equivalent load is calculated for each main bearing by summing the incremental loads ( $1, \mathrm{p} 2, \ldots \mathrm{pN})$ on each adjacent crankpin, at the respective angular increment (i1,i2, ...iN). The weighted average or Equivalent Load for each main bearing is calculated in the same manner as the crankpin bearing Equivalent Load.

The loading of the crankshaft thrust bearing and all camshaft support bearings is considered relatively low and easily capable of being supported by a roller bearing that utilizes the space available. For this reason, no attempt was made to calculate either bearing loads or lives for these positions.

To maintain an engine configuration as nearly stock production as possible, this project used the stock crankshaft with only its heat treatment changed to support the use of roller bearings. This one-piece forged crank configuration, with the exception of the front main bearing, requires the use of split main and crankpin bearings. 
The size constraints of the crankpin bearing suggested the highest calculated bearing life that might be expected in the neighborhood of 300 hours. To maximize bearing load rating, the largest rolling element diameter possible was utilized by insuring the connecting rods were fabricated with the largest big end that will still rotate freely within the engine block. This resulted in the use of a bearing with a $5 \mathrm{~mm}$ diameter rolling element. The total length of the crankpin bearing was made to allow a clearance fit within the crank cheeks of the crankpin journals. The cage material selected was a high temperature, high-strength engineered polymer used in other engine crankpin bearing applications. Using standard polymer cage design practice, the designed incorporated the maximum number of $5 \mathrm{~mm}$ diameter rollers of the maximum length possible in order to maximize the bearing's load rating. This design resulted in a calculated bearing $\mathrm{L}_{10}$ life of just under 300 hours. The resulting bearing design is shown in Figure 4-1.

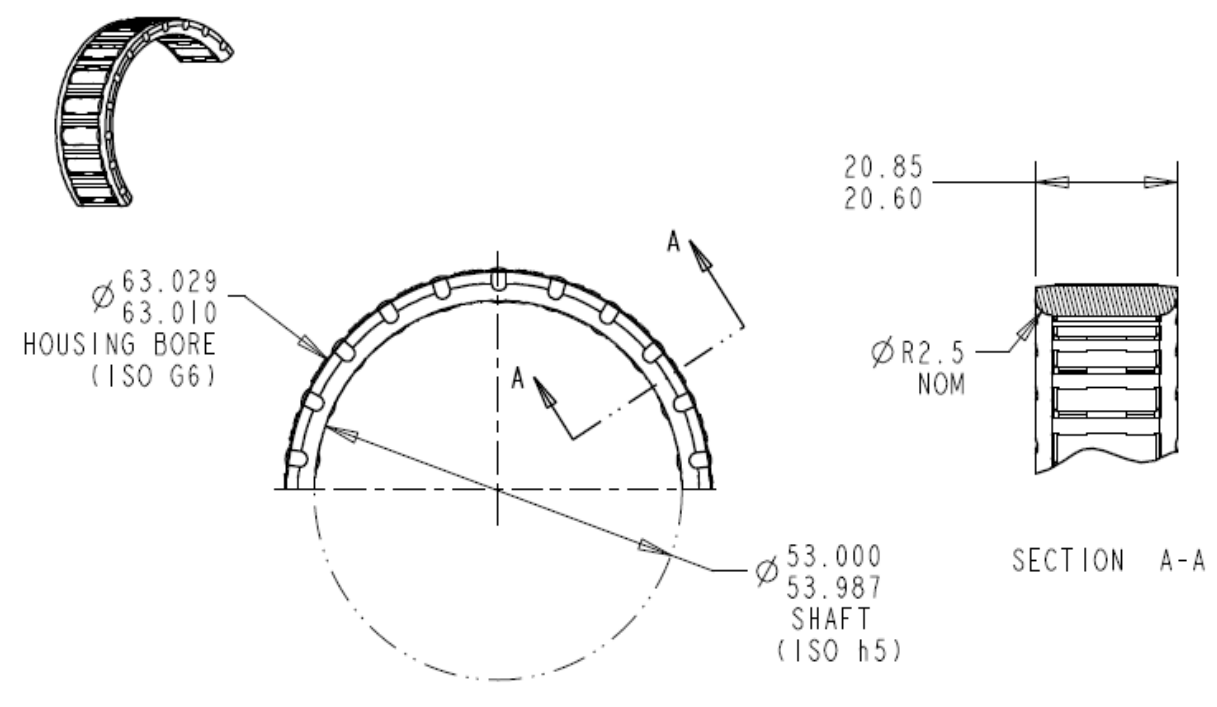

Figure 4-1: Crankpin Bearing.

The calculated main bearing life, as with the crankpin bearing, suggested relatively low $L_{10}$ hours. The two center main bearing positions produce the lowest $\mathrm{L}_{10}$ life because they are loaded by crankpins on both sides as opposed to the two end main positions which are only loaded by a crankpin on one side. Again, the size of the stock crankshaft main journals, as well as limiting the main bearing outer rings to $3 \mathrm{~mm}$ cross section, narrowed the choice of rolling element diameter to $5 \mathrm{~mm}$. A polyamide was selected as the main bearing cage material. Using standard polymer cage design practice, the maximum number of $5 \mathrm{~mm}$ diameter rollers of the maximum length possible was chosen in order to maximize the bearing's load rating. This resulted in a calculated bearing $\mathrm{L}_{10}$ life of about 70 hours for the most heavily loaded main bearing position. The main bearing is shown in Figure 4-2. 


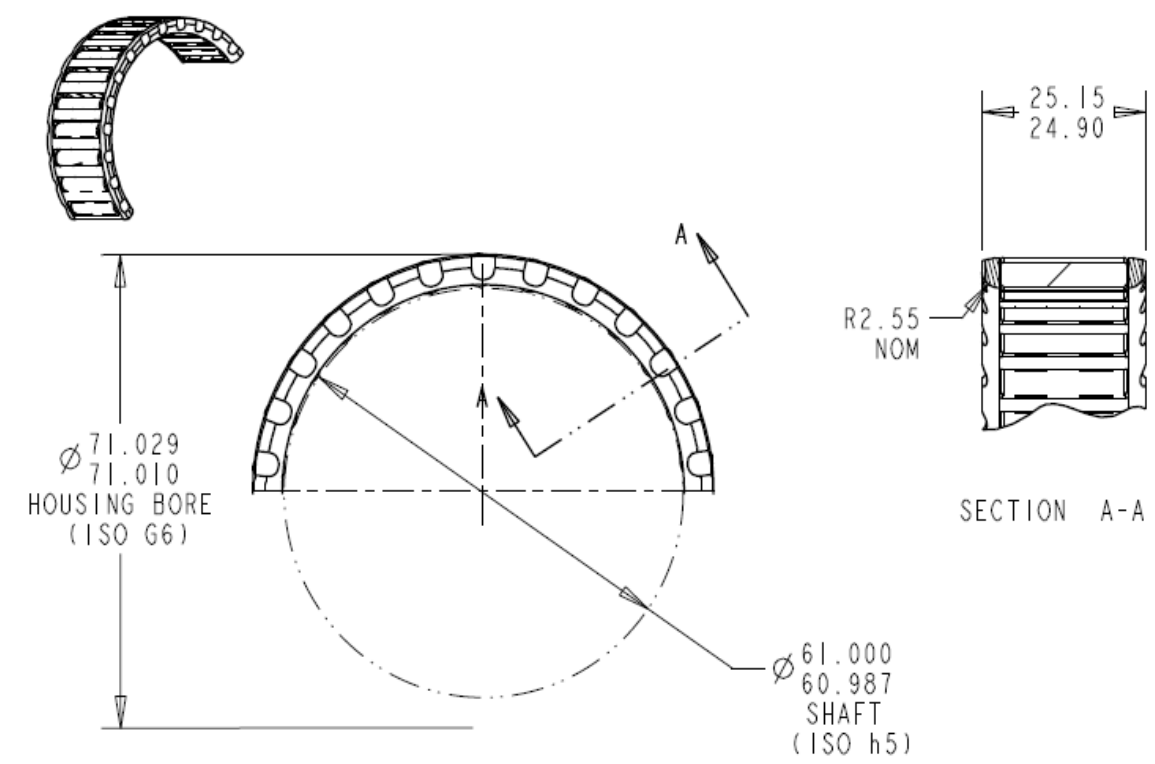

Figure 4-2: Main Bearing.

The available thrust surface for the crankshaft thrust bearing in the stock engine was consumed by the large size of the new main roller bearing. To provide a bearing to react to any crank thrust, a pair of catalog, needle thrust bearings were applied to the area just forward of the front bulkhead and rearward of the tone wheel. Appropriate hardware was designed and fabricated to mount this arrangement as shown in Figure 4-3.
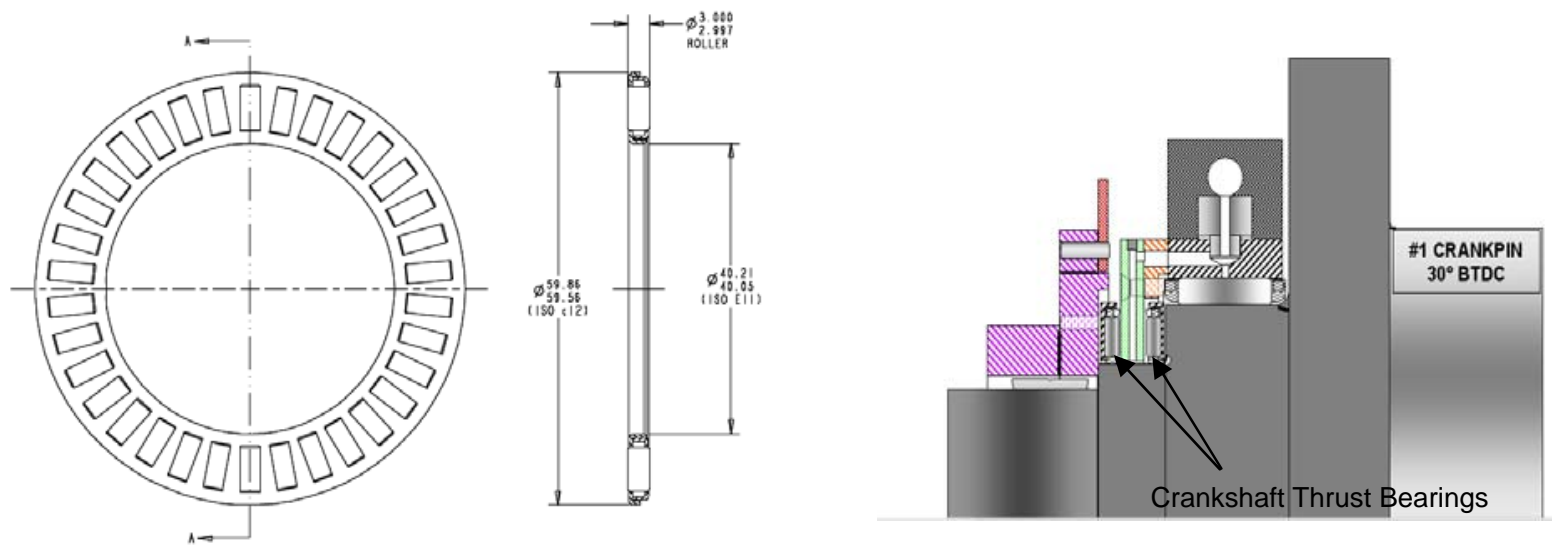

Figure 4-3: Crankshaft Thrust Bearings. 
The front camshaft support bearing was a full-complement drawn cup bearing designed to fit within a cartridge containing seal rings (Figure 4-4) to control the oil flow to the engine's hydraulic phasers. The remaining camshaft support bearings are made using $2.5 \mathrm{~mm}$ rolling elements and a single, split, polyamide cage to allow installation and are used with split outer rings similar in design to the split main bearing outer rings. The four camshafts were fabricated specifically for this project and the stock cam carrier was modified to accept the new bearing configurations.
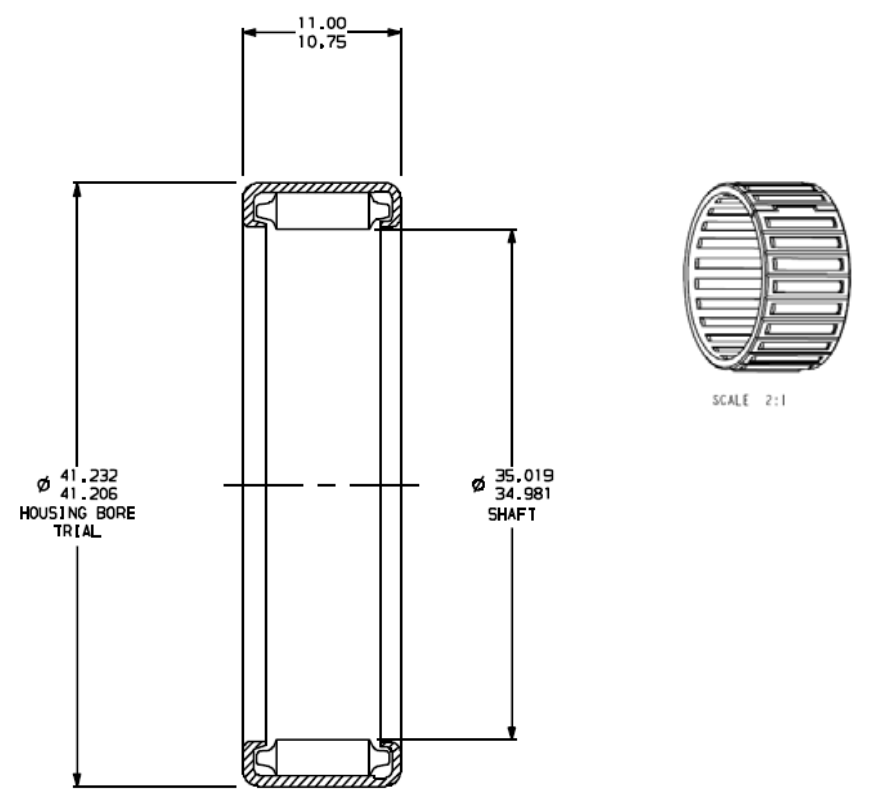

Figure 4-4: Camshaft Support Bearing. 


\section{TASK 5}

\section{Timken/FEV Crankshaft Selection \& Manufacture}

A total of 30 forged, unground crankshafts were procured from Toyota with the anticipation that some work would be needed to develop a heat treatment process to deliver the desired hardness.

Related to this Study, Timken had worked with other suppliers including those skilled in the practices of heat treating automotive crankshafts. InductoHeat was selected as a specific supplier of heat treat technology. The work done by the team to apply that technology to the production line engine components is reported in this section.

\section{Crankshaft:}

The strong preference was to utilize stock forgings for the crankshaft of the test engine as Timken as the material supplier to Toyota was familiar with the steel grade, and hence could better predict its response to heat treatment. InductoHeat was engaged to apply their induction heating and rapid quench technology to boost the hardness of the roller bearing surfaces to the desired level for best fatigue performance with minimal additional processing. It was recognized that the hardness level would fall slightly when the cranks were tempered. Considerable time was spent in design and trials to achieve the desired hardness profile in and around the raceway without altering the properties or dimensions of the crankshaft. Figure 5-1 shows the improvement that was made in the hardness profile (light areas).

Due to the complex shape and mass, achieving the desired hardness with a uniform profile extending from the raceway to the crankshaft cheeks on all journals proved difficult. Although InductoHeat's mission was to harden the journal area that would be contacted by the roller, the challenge was later posed to harden the fillet area. In the end, InductoHeat's best effort produced a crank with a hardness level slightly below the desired level as expected with a profile that covered the raceway and into the fillet.

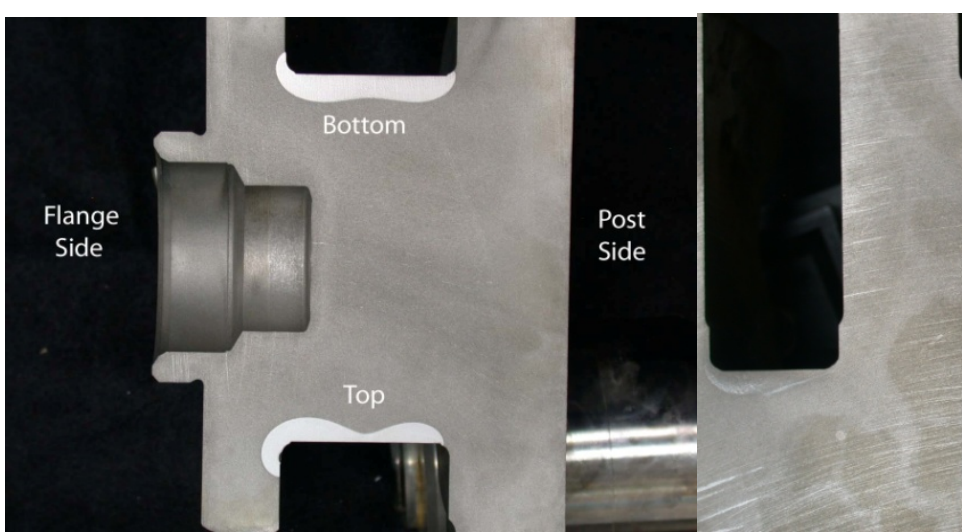

(a)

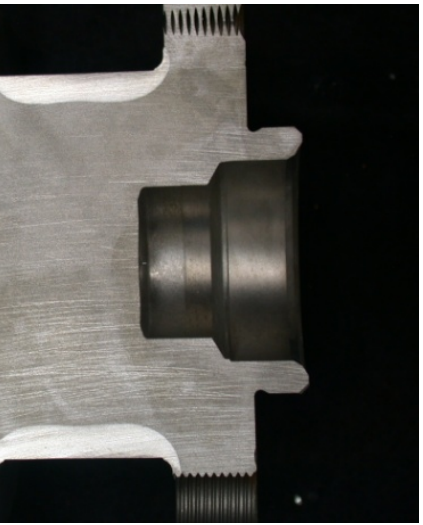

(b)

Figure 5-1: Crankshaft Section Showing Hardened Zones

(a) Early Attempt and (b) Refined Process 


\section{TASK 6}

\section{Timken Engine Testing}

The planned engine testing to be performed by Timken was to utilize the production and rollerized display engines. Both display stands were outfitted with provisions to measure the power required to spin the crank over a speed range of 500 to $1200 \mathrm{rpm}$. Preliminary figures indicated that the rollerized engine was running at $1 / 3$ less friction than the standard engine.

Due to the fact that the rollerized engine was damaged in shipment and because the focus of the team's efforts was shifted to engine performance issues, the testing using the displays was cut short. After the preliminary friction measurement, no further measurements were made to compare basic friction and noise level of the rollerized and production engines. 


\section{TASK 7}

\section{FEV Engine Testing}

The performance of the plain bearing and roller bearing Toyota 3.5L V-6 Avalon engines was evaluated on an engine dynamometer and in the vehicle. This work was contracted to FEV Engine Technology. The testing was to include measurement of fuel consumption across the engine map of loads and speeds, friction measurements on a motored system and component friction using a so-called strip test, and finally a noise, vibration and harshness (NVH) assessment. The plain bearing engine was tested in vehicle prior to being pulled for dynamometer testing. The rollerized engine was to complete engine dynamometer testing, followed by evaluation in vehicle.

The complete program of planned testing was as follows:

- Baseline Production Engine

o Engine-Level Testing

- Friction

- Mapping

o Vehicle-Level Testing

- Noise, Vibration and Harshness

- Emissions/FE

- Cold Start \& Performance

- Rollerized Engine

o Engine-Level Testing

- Friction

- Mapping

- Noise, Vibration \& Harshness

- Durability

o Vehicle-Level Testing

- Noise, Vibration and Harshness

- Emissions/FE

- Cold Start \& Performance

\section{BSFC Mapping}

The process of mapping an engine consists of systematically running a defined engine speed and load map to create a grid that captures the entire operating area of the engine. At each speed and load, all defined measurements are collected and can be displayed as a changing surface over engine operating points. These Brake Specific Fuel Consumption (BSFC) measurements are collected according to the grid shown in Table 7-1. 
Table 7-1: Grid of BSFC Engine Mapping Points.

\begin{tabular}{|c|c|c|c|c|c|c|c|c|c|}
\hline WOT & & & & $x$ & $x$ & $x$ & $x$ & $x$ & $x$ \\
\hline 10 & & & & $x$ & $x$ & $X$ & $X$ & $X$ & $x$ \\
\hline 8 & & & & $x$ & $X$ & $x$ & $x$ & $x$ & $x$ \\
\hline 6 & & & & $X$ & $X$ & $X$ & $X$ & $X$ & $X$ \\
\hline 5 & & $X$ & & $X$ & $x$ & $X$ & & & \\
\hline 4 & & $X$ & & $X$ & $x$ & $X$ & $x$ & $X$ & $X$ \\
\hline 3 & & $x$ & & $X$ & $X$ & $X$ & & & \\
\hline 2.5 & & $X$ & & $X$ & $x$ & & & & \\
\hline 2 & & $X$ & & $X$ & $X$ & $X$ & & & \\
\hline 1.5 & & $X$ & & $x$ & $X$ & & & & \\
\hline 1 & & $X$ & & $X$ & $x$ & & & & \\
\hline IDLE & $x$ & & $x$ & & & & & & \\
\hline & 700 & 1000 & 1200 & 1500 & 2000 & 2500 & 4000 & 5000 & 6000 \\
\hline
\end{tabular}

All test runs were conducted with the same boundary conditions. Mineral 5W-30 oil was utilized. Oil temperatures were allowed to self-set and stabilize at each mapping point. An oil cooler was installed to keep maximum temperature below $130 \mathrm{C}$.

A green 50/50 mix of glycol and $\mathrm{H}_{2} \mathrm{O}$ was used for engine coolant. The production thermostat was operating to set engine temperature throughout the entire testing. A SuperFlow liquid to liquid heat exchanger was used to act as the radiator for cooling the engine coolant.

Intake air pressure, temperature and humidity were controlled in a sealed air system to 1000 mbar, $25 \mathrm{C}$, and 47grains/lb humidity at the air filter inlet to the engine. Simulated exhaust backpressure was created by use of a single butterfly valve. The butterfly valve was set to match the exhaust backpressure at $6000 \mathrm{rpm}$ wide open throttle (WOT) for the production engine and left at that setting throughout the entire testing.

\section{Production Avalon Baseline BSFC Results}

The primary method used to determine friction levels of the base production Avalon engine was to use BSFC. The BSFC parameter accounts for the amount of fuel (energy in) used by an engine and the resulting output torque (energy out) and is reported in a $\mathrm{g} / \mathrm{kWhr}$ unit. The two main factors in generating low fuel usage are an efficient combustion process and low mechanical friction in the engine. If the combustion process is unchanged, then the changes in BSFC are due to mechanical friction differences. 
Prior to engine mapping, the production engine was subject to a 4,000 mile in-vehicle break-in. The BSFC mapping showed that the Avalon V6 performs very well when compared against similar engines in the subcontractor's database. At a standard $2000 \mathrm{rpm}$ speed with 2 bar BMEP (Brake Mean Effective Pressure) load, the engine BSFC measured in the bottom 1/3 of the population of similar engines tested. This result is shown below in Figure 7-1. Overall, the engine's BSFC performance is better than average in class and at its most efficient point is near best in class. The baseline engine is a very efficient platform which makes it a good candidate on which to prove roller bearing technology.
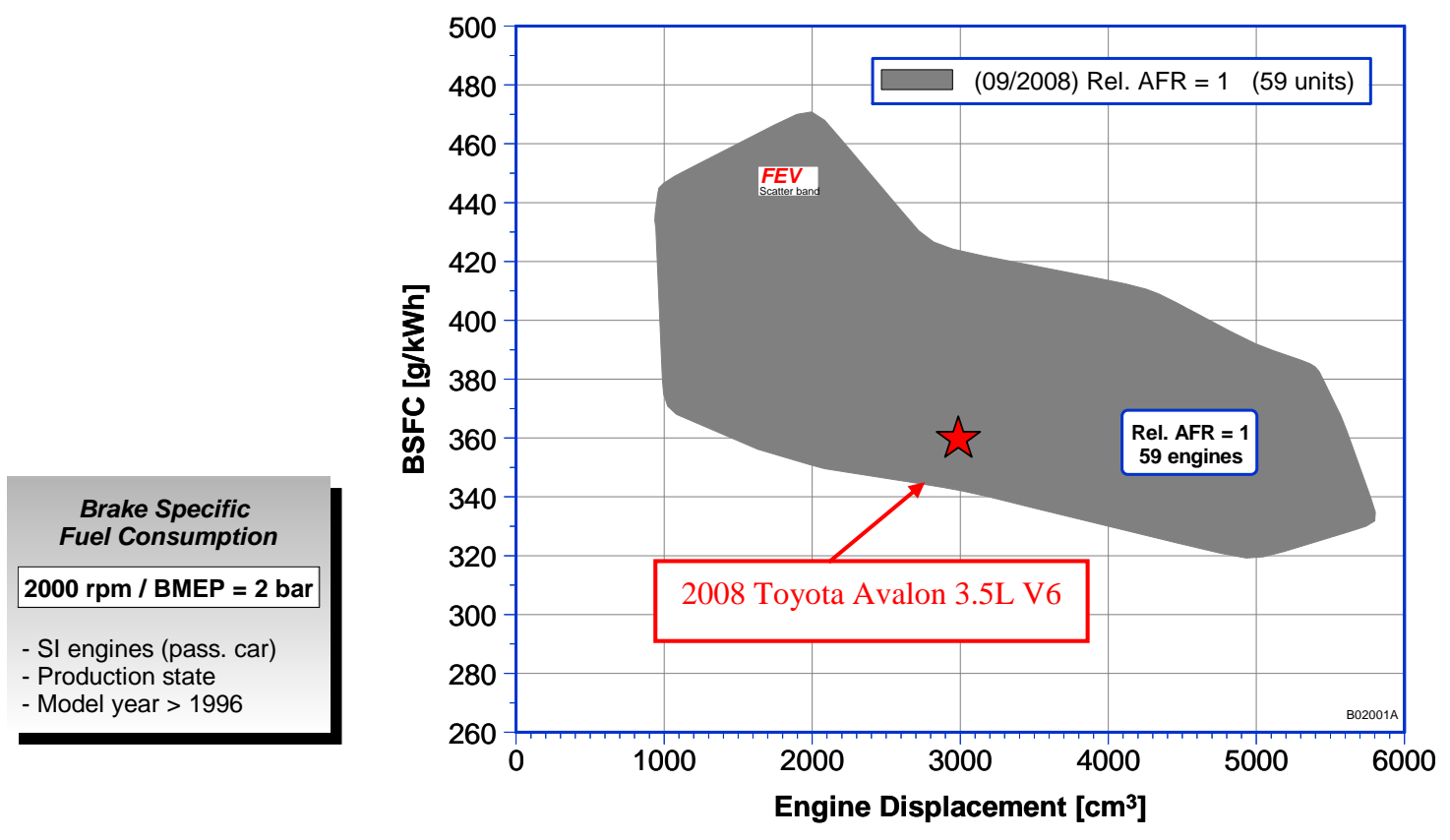

Figure 7-1: 2000 rpm with 2 Bar Load BSFC Data Point for Baseline Engine Compared to Database of Similar Engines.

\section{Roller Bearing Avalon Baseline BSFC Results}

The roller bearing BSFC measurements did not show the improvement in fuel consumption that was expected. This test plan uncovered challenges with the system design that were not anticipated or foreseen based on previous experience. Subsequent testing and evaluation revealed that there were insufficient resources to properly address the design issue and resolve the problem to a level necessary to properly show the benefit of the roller bearing application. Evaluation of the bearings and the bearing mating surfaces did not indicate any abnormal conditions that were indicative of root cause for the problems. 


\section{Motored Friction Strip Testing}

The strip method consists of disassembling the engine in a systematic method to measure the friction losses of the components. These measurements are carried out to determine the mechanical friction of the different engine components independent of gas exchange losses and the temperatures and pressures from combustion.

These measurements were completed for each component as shown in the work schedule below in Table 7-2. All tests were conducted with 5W-30 engine oil. The test runs were conducted at multiple temperatures in a given speed range.

Table 7-2: Measurement Work Schedule.

\begin{tabular}{|l|l|l|c|}
\hline \multicolumn{2}{|l|}{ Measurements } & Evaluation & Difference \\
\hline 1 & Complete Engine Motored with gas exchange losses & Oil pressures \& flow & $-/$ - \\
\hline 2 & Crank train & Crank train & - \\
\hline 3 & Crankshaft with Master Weights (m.w.) & Pistons \& Connecting Rods & $2-3$ \\
\hline 4 & Crankshaft and valvetrain with drive & Valvetrain incl. drive & $4-3$ \\
\hline 5 & Crankshaft + Oil pump (loaded) & Oil Pump (loaded) & $5-3$ \\
\hline
\end{tabular}

Motored Friction Test Bench and Test Equipment

$\underline{\text { Test Bench }}$

- Special test bench used for motored engine investigations (Figure 7-2)

- Electric Motor: 8000 rpm maximum speed, 200 Nm maximum driving torque

\section{Coolant Circuit}

- Engine connected to an external heating and cooling system

- Coolant temperature maximum $120 \mathrm{C}+/-1 \mathrm{C}$

\section{Oil Circuit}

- External oil system used to test without the internal oil pump.

- Oil temperature and pressure in the main gallery are controlled. Feedback loop is through the oil sump.

- Oil Temperature Maximum = $135 \mathrm{C}+/-1 \mathrm{C}$ 


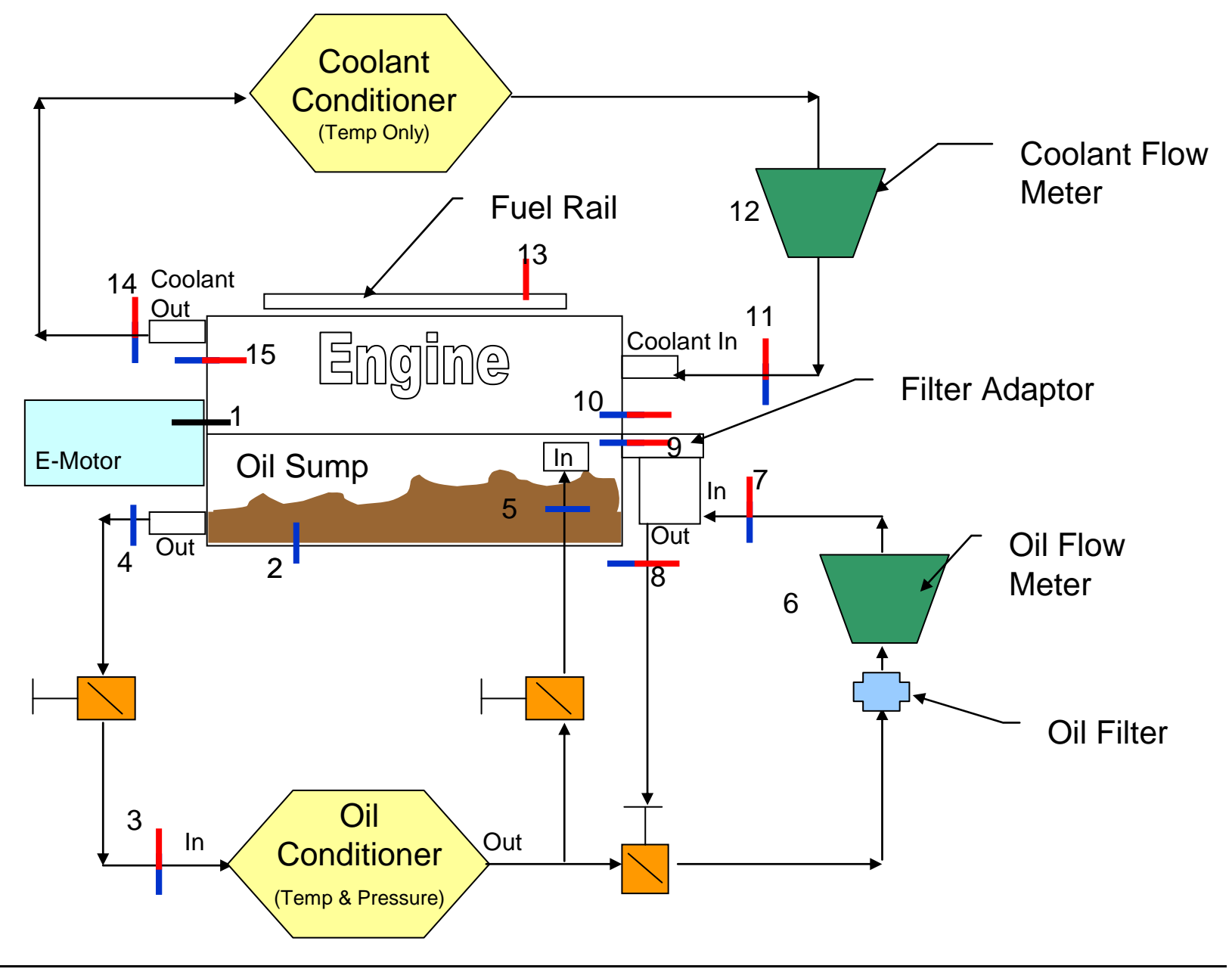

\section{Legend}

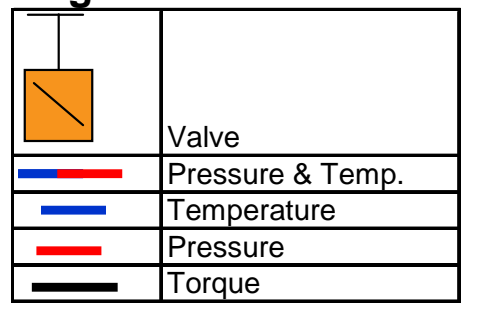

\begin{tabular}{|l|l|c|}
\hline Description & Unit & Location \\
\hline M_TRQENG & $\mathrm{Nm}$ & 1 \\
\hline M_CoolantFlow & $\mathrm{g} / \mathrm{min}$ & 12 \\
\hline M_Oil_Flow_MTR & $\mathrm{L} / \mathrm{min}$ & 6 \\
\hline T_COOLIN & ${ }^{\circ} \mathrm{C}$ & 11 \\
\hline T_COOLOUT & ${ }^{\circ} \mathrm{C}$ & 14 \\
\hline T_OIL_MAINGAL & ${ }^{\circ} \mathrm{C}$ & 10 \\
\hline
\end{tabular}

\begin{tabular}{|l|l|c|}
\hline Description & Unit & Location \\
\hline T_OILFILTEROUT & ${ }^{\circ} \mathrm{C}$ & 8 \\
\hline T_OILFILTERGALL & ${ }^{\circ} \mathrm{C}$ & 9 \\
\hline T_OILGALLEYHEAD & ${ }^{\circ} \mathrm{C}$ & 15 \\
\hline T_OILCONFEED & ${ }^{\circ} \mathrm{C}$ & 3 \\
\hline T_OILSUMP & ${ }^{\circ} \mathrm{C}$ & 4 \\
\hline T_OILPANRET & ${ }^{\circ} \mathrm{C}$ & 5 \\
\hline
\end{tabular}

\begin{tabular}{|l|l|c|}
\hline Description & Unit & Location \\
\hline T_OILPAN & ${ }^{\circ} \mathrm{C}$ & 2 \\
\hline P_COOLIN & Bar G & 11 \\
\hline P_COOLOUT & Bar G & 14 \\
\hline P_OILMAINGAL & Bar G & 10 \\
\hline P_CYLHEADOIL & Bar G & 2 \\
\hline P_OILFILTERGALL & Bar G & 9 \\
\hline
\end{tabular}

\begin{tabular}{|l|l|c|}
\hline Description & Unit & Location \\
\hline P_OILFILTEROUT & Bar G & 8 \\
\hline P_OILCONFEED & Bar G & 3 \\
\hline P_FUELRAIL & Bar A & 13 \\
\hline
\end{tabular}

Figure 7-2: Test Bench Schematic 


\section{Production Avalon Baseline Motored Friction Results}

The production Avalon V6 engine chosen for this study was successfully characterized to determine its operating friction levels. Comparing this engine to others of similar architecture in the subcontractor's engine database, the subject engine measured near the best engines in the collection for cranktrain isolated friction. This is shown in Figure 7-3.

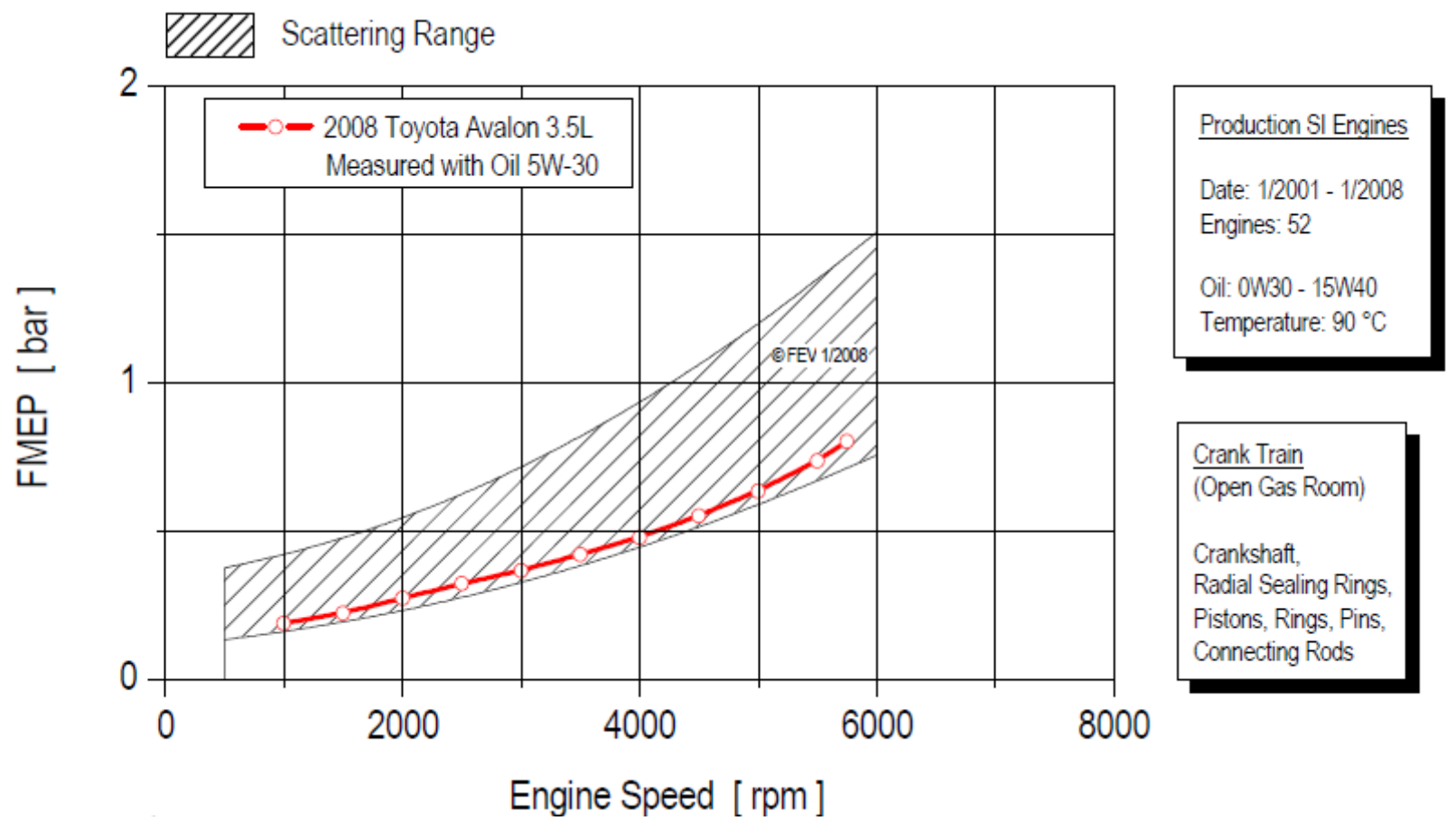

Figure 7-3: Baseline Engine Cranktrain Friction Comparison Against Subcontractor Database of Similar Engines.

Roller Bearing Avalon Baseline Motored Friction Results

To further troubleshoot the engine, the dynamometer BSFC testing was halted and friction evaluation in motored strip down testing performed. The strip testing did show indication of the roller bearings benefit in the system, however the benefit demonstrated did not meet expectations based on prior experiences. Timken would expect based on prior studies and experience to see $20 \%$ or greater improvement in motoring friction at engine operating temperatures. The $5-10 \%$ benefit shown in this testing was an indication that the same system issues that affected the fuel consumption results were also affecting the motored friction results. 
Motored friction testing was performed at multiple temperatures to compare the roller engine benefit at cold start and normal temperature operation of the engine. As expected and shown in Figure 7-4, the benefit from the roller bearings is more significant at low oil temperatures. The data also shows that as engine operating temperature is lowered, the friction benefit realized by roller bearings in the cranktrain is increased. This benefit can be realized during cold starts and should improve cycle efficiency and enable vehicle system improvements like reduction in starter motor size, cabling, and battery size for non-hybrid conventional applications. Hybrid applications will benefit from less battery usage to start the engine during start and stop cycles.

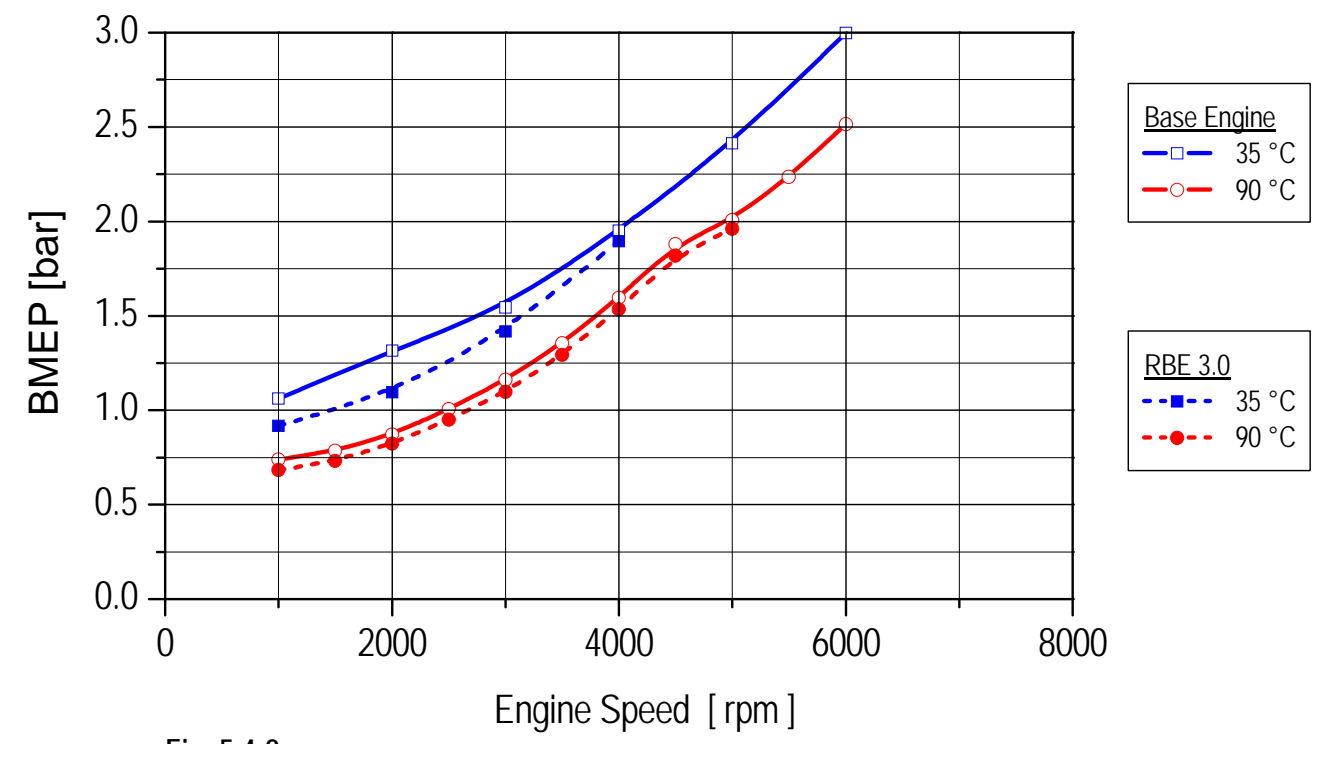

Figure 7-4: Motorized Friction Comparison of Production and Rollerized Engines at Two Temperatures.

\section{In Vehicle NVH Testing}

For the purpose of assessing the NVH baseline characteristics of the Toyota Avalon powertrain and vehicle the following instrumentation was installed:

- Customer interface assessment (see Figure 7-5):

o Microphone at driver's outer (left) ear - measurement of sound pressure as heard by the customer

o Accelerometer on seat track - assessment of tactile input to the driver's seat

o Accelerometer on steering wheel - assessment of tactile input to the steering wheel

- Powertrain level measurement (see Figure 7-6):

o Accelerometer on active side of engine mounts - assessment of structure borne inputs to vehicle 

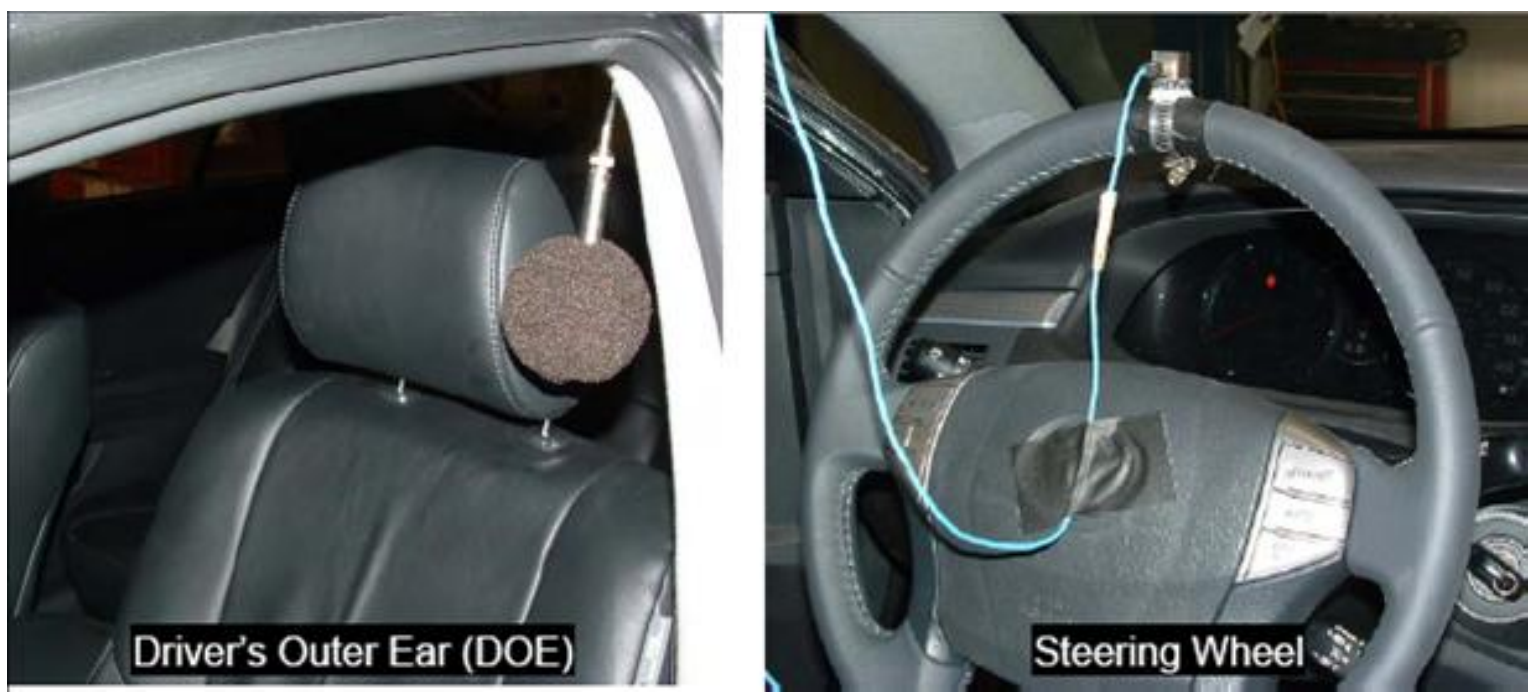

Figure 7-5: Customer Interface NVH Instrumentation
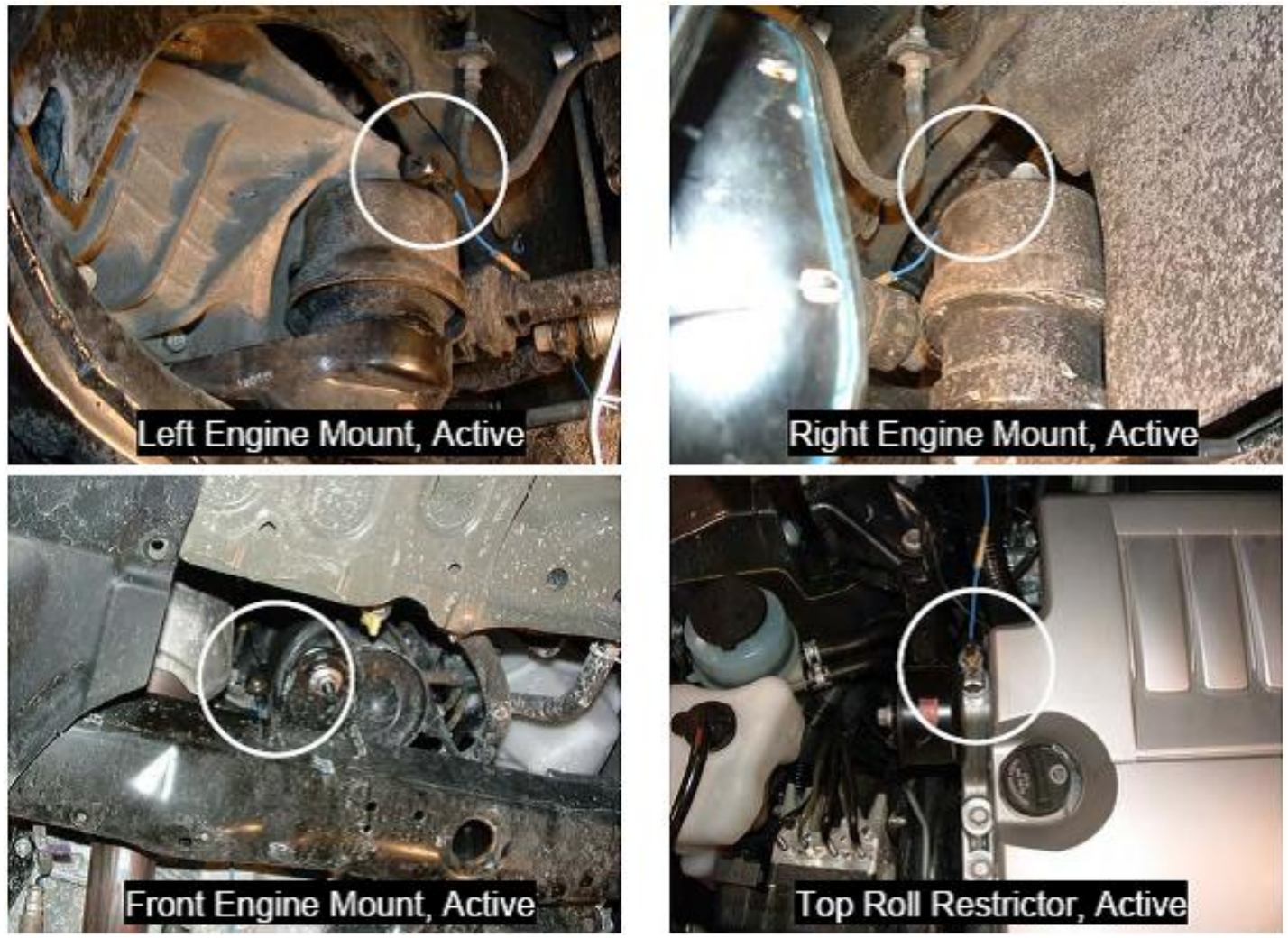

Figure 7-6: Powertrain NVH Instrumentation 


\section{Production Avalon Baseline Results}

An NVH assessment of the production Toyota Avalon vehicle was conducted to establish a baseline with which a roller bearing engine could be compared. This would facilitate assessment of relative NVH performance and identification of any roller bearing specific NVH issues. All measurements were acquired on a four-wheel, hemi-anechoic chassis dynamometer. The following operating conditions were included in the assessment of the baseline vehicle $\mathrm{NVH}$ characteristics:

- $\quad$ Full Load Speed Sweep ( $2^{\text {nd }}$ Gear $)$

- Coast Down Speed Sweep $\left(2^{\text {nd }}\right.$ Gear $)$

- Idle:

\section{o Park: Accessories On/Off \\ o Drive: Accessories On/Off}

The production Avalon's performance was successfully characterized and compared to the subcontractor's database of similar vehicles. The NVH characteristics of the vehicle and powertrain were assessed under full load acceleration. The overall sound pressure and articulation index are shown in Figure 7-7. As shown in this figure, the sound pressure levels are moderate to high relative to the subcontractor scatterband for large gasoline vehicles.
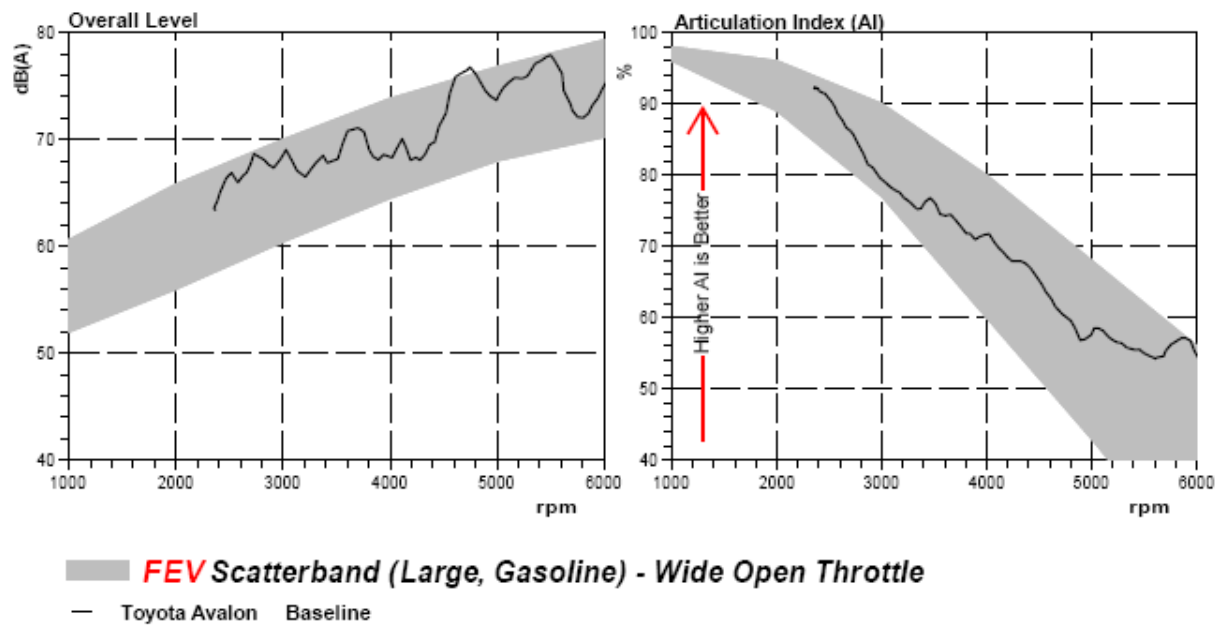

Figure 7-7: Full Load Speed Sweep - Driver’s Ear Sound Pressure and AI

The frequency and order content of the driver's ear sound pressure is shown in Figure 7-8. This data shows a strong resonance near $270 \mathrm{~Hz}$. This resonant content is apparent in the $3^{\text {rd }}$ and $3.5^{\text {th }}$ orders which drive the high speed peaks observed in the overall level.

The interpretation of the NVH data was that while the engine is not particularly quiet, the Toyota engineers have successfully minimized the $\mathrm{NVH}$ transfer to the passenger cabin so that the vehicle appears to be a quiet car. This could be an advantage as that system could also dampen roller bearing noise. 

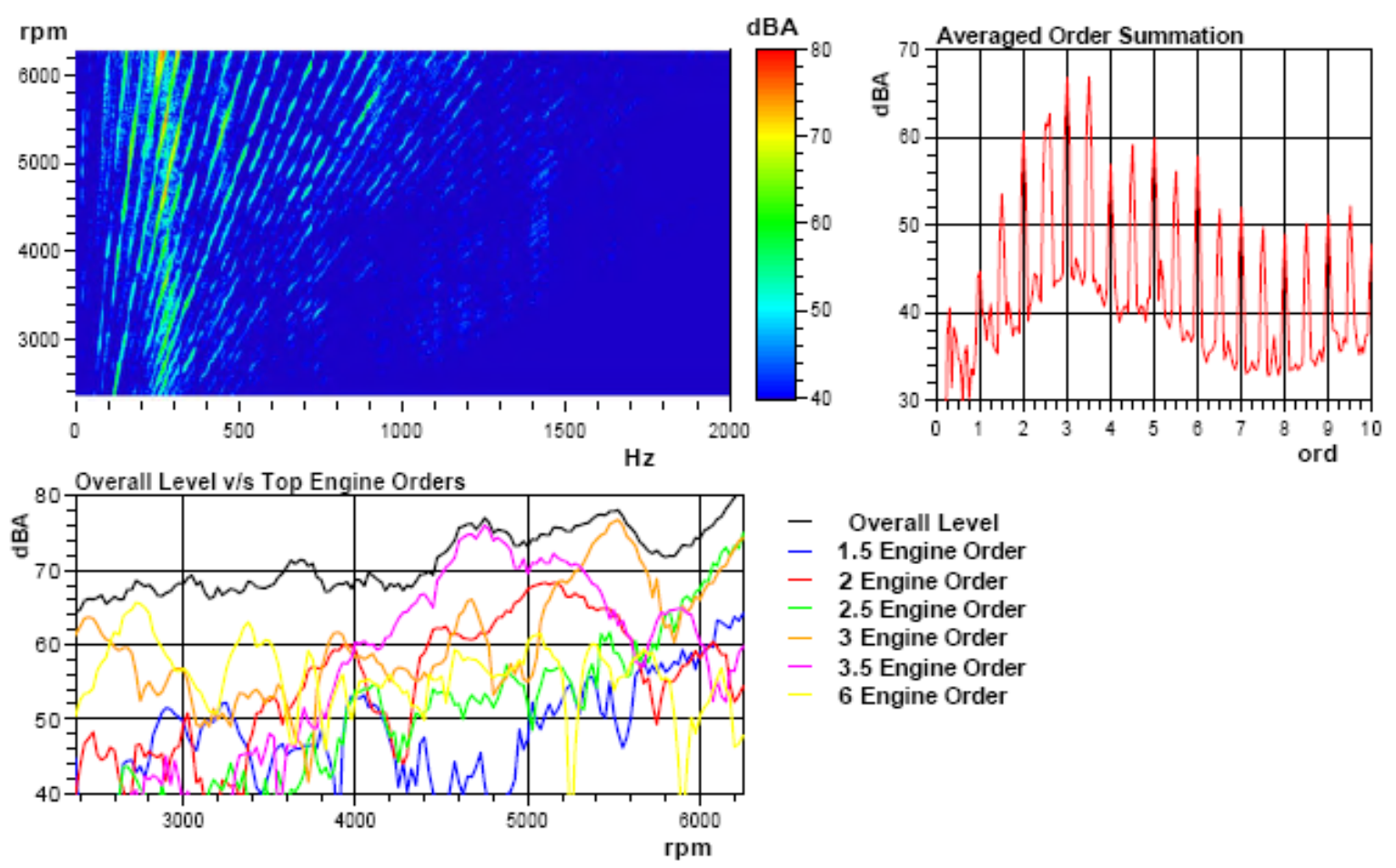

- Overall Level

- 1.5 Engine Order

- 2 Engine Order

- 2.5 Engine Order

- 3 Engine Order

- 3.5 Engine Order

6 Engine Order

Figure 7-8: Full Load Speed Sweep - Driver’s Ear Frequency Content

\section{Roller Bearing Avalon NVH Results}

The NVH testing was to take place at the conclusion of BSFC mapping and friction strip test assessment. Due to problems encountered in those tests and efforts to troubleshoot the issues with the engine, no testing of the roller bearing engine for $\mathrm{NVH}$ performance was completed.

\section{Summary of Testing at FEV}

The remainder of the planned testing (NVH, BSFC of the roller engine) was not completed due to delays and the issues encountered in the early stages of testing. Further work will be required to achieve the reliability and performance that all involved fully expected.

Subsequent teardown and inspection of the roller bearing Avalon engine revealed the potential sources of the excessive friction in the experimental application. These features would have been eliminated in the development level design and the team is confident (based on prior and current other experiences) that expected friction reduction could be realized in this application with modified hardware.

Should an opportunity exist to further develop this application, the Timken team is confident that redesigned components can be used to fix the issues encountered. This would allow quantification of the benefits to fuel consumption that roller bearings can provide. Additionally important work on the challenging problems of $\mathrm{NVH}$ and extended life durability can also be investigated. 


\section{ITEM D}

\section{ACCOMPLISHMENTS}

The project team successfully demonstrated the ability to package roller bearings satisfactorily in numerous locations in a typical automotive internal combustion engine. Many friction tests were conducted of the rollerized engine and its later modifications aimed at identifying an apparent friction problem. Since no improvement was seen in the results of fired tests, the full tests to map performance of the rollerized engine on the dynamometer and in the vehicle were not conducted.

Measurements were made mapping the performance of the production engine and of the $\mathrm{NVH}$ characteristics of the production vehicle. Since the testing of the rollerized engine did not advance to the same stage, the data from the production vehicle tests will not be reported in this report except to say that the measured values fell within the FEV's experience band for that class and vintage of engine. Tests of the production vehicle scheduled for later in the program were canceled when it was clear that no comparison would be made.

\section{ITEM E}

\section{SUMMARY \& CONCLUSIONS}

The rollerized engine operated within normal parameters, so the application of roller bearings with the necessary engine modifications was judged to have been a success.

The test results measured when the engine was powered by an external motor confirmed the results of earlier studies which showed that application of roller bearings to an ICE does reduce friction, although the 5-10\% reduction was less than the amount seen in other studies.

Fired testing of the rollerized engine failed to show the expected friction benefit. Evidence of excessive friction was seen after test, but there were no abnormal bearing conditions that suggested a root cause. Limited project resources prohibited resolution of the friction issue.

\section{ITEM F}

\section{RECOMMENDATIONS}

Should an opportunity arise to develop this application further, the recommendation is to adopt a redesign approach as opposed to maximizing use of production components.

The scope of this project did not include durability demonstration and that subject would have to be addressed in any follow-on work. 
This Page Intentionally Left Blank

LFE Final Technical Report 